\title{
A Comparison of Experimental and Broken Symmetry Density Functional Theory (BS-DFT) Calculated Electron Paramagnetic Resonance (EPR) Parameters for Intermediates Involved in the S2 to S3 State Transition of Nature's Oxygen Evolving Complex
}

DOI:

10.1021/acs.jpcb.7b10843

\section{Document Version}

Accepted author manuscript

Link to publication record in Manchester Research Explorer

Citation for published version (APA):

Beal, N. J., Corry, T., \& O'Malley, P. J. (2018). A Comparison of Experimental and Broken Symmetry Density Functional Theory (BS-DFT) Calculated Electron Paramagnetic Resonance (EPR) Parameters for Intermediates Involved in the $S_{2}$ to $S_{3}$ State Transition of Nature's Oxygen Evolving Complex. Journal of Physical Chemistry $B$, 122(4), 1394-1407. https://doi.org/10.1021/acs.jpcb.7b10843

Published in:

Journal of Physical Chemistry B

\section{Citing this paper}

Please note that where the full-text provided on Manchester Research Explorer is the Author Accepted Manuscript or Proof version this may differ from the final Published version. If citing, it is advised that you check and use the publisher's definitive version.

\section{General rights}

Copyright and moral rights for the publications made accessible in the Research Explorer are retained by the authors and/or other copyright owners and it is a condition of accessing publications that users recognise and abide by the legal requirements associated with these rights.

Takedown policy

If you believe that this document breaches copyright please refer to the University of Manchester's Takedown Procedures [http://man.ac.uk/04Y6Bo] or contact uml.scholarlycommunications@manchester.ac.uk providing relevant details, so we can investig PUEC

ACCESS 


\title{
A Comparison of Experimental and Broken Symmetry Density Functional Theory (BS-DFT) Calculated Electron Paramagnetic Resonance (EPR) Parameters for Intermediates Involved in the $S_{2}$ to $S_{3}$ State Transition of Nature's Oxygen Evolving Complex
}

Nathan J. Beal, Thomas A. Corry and Patrick J. O’Malley*

School of Chemistry, The University of Manchester, Manchester M13 9PL, UK.

\begin{abstract}
A broken symmetry density functional theory (BS-DFT) magnetic analysis of the $\mathrm{S}_{2}, \mathrm{~S}_{2} \mathrm{Y}_{\mathrm{Z}} \bullet$ and $S_{3}$ states of Nature's oxygen evolving complex is performed for both the native $\mathrm{Ca}$ and Sr substituted forms. Good agreement with experiment is observed between the tyrosyl calculated g-tensor and ${ }^{1} \mathrm{H}$ hyperfine couplings for the native $\mathrm{Ca}$ form. Changes in the hydrogen bonding environment of the tyrosyl radical in $\mathrm{S}_{2} \mathrm{Y}_{\mathrm{Z}^{\bullet}}$ caused by $\mathrm{Sr}$ substitution leads to notable changes in the calculated g-tensor of the tyrosyl radical. Comparison of calculated and experimental ${ }^{55} \mathrm{Mn}$ hyperfine couplings for the $\mathrm{S}_{3}$ state presently favours an open cubane form of the complex with an additional $\mathrm{OH}$ ligand coordinating to $\mathrm{Mn}_{\mathrm{D}}$. $\mathrm{In} \mathrm{Ca}$ models this additional ligation can arise by closed-cubane form deprotonation of the $\mathrm{Ca}$ ligand $\mathrm{W} 3$ in the $\mathrm{S}_{2} \mathrm{Y}_{\mathrm{Z}^{\bullet}}$ state accompanied by spontaneous movement to the vacant $\mathrm{Mn}$ coordination site or by addition of an external $\mathrm{OH}$ group. For the $\mathrm{Sr}$ form, no spontaneous movement of W3 to the vacant Mn coordination site is observed in contrast to the native Ca form; a difference which may lead to the reduced catalytic activity of the Sr substituted form. BS-DFT studies on peroxo models of $\mathrm{S}_{3}$ as indicated by a recent X-ray free electron
\end{abstract}


laser (XFEL) crystallography study give rise to a structural model compatible with experimental data and an $\mathrm{S}=3$ ground state compatible with EPR studies.

\section{Introduction}

During oxygenic photosynthesis, for each visible light excitation of Photosystem II, the primary donor chlorophyll complex, $\mathrm{P}_{680}$, forms a strongly oxidising radical cation $(\mathrm{P}$. $\left.680^{\bullet+}\right) .{ }^{1}$ This radical cation oxidises a nearby tyrosine residue $\left(\mathrm{Y}_{\mathrm{Z}}, \mathrm{D} 1-\mathrm{Tyr}-161\right)$ to form a tyrosyl radical $\left(\mathrm{Y}_{\mathrm{Z}}^{\bullet}\right)$ which under physiological conditions can subsequently one-electron oxidise the oxygen evolving complex (OEC) and advance this $\mathrm{Mn}_{4} \mathrm{CaO}_{5}$ cluster to the next $\mathrm{S}_{\mathrm{n}}$ state of the Kok cycle, Figure $1 .^{2,3}$ Cryogenic temperatures (typically below $20 \mathrm{~K}$ ) significantly perturb this single electron transfer between $\mathrm{Y}_{\mathrm{Z}}$ and the OEC and may subsequently block the Kok cycle advancement from $S_{n} Y_{Z}{ }^{\bullet}$ to $S_{n+1} Y_{Z} \cdot{ }^{4-9}$ In a similar fashion these trapped intermediates can be obtained with various chemical modifications of the sample such as $\mathrm{Ca}$ depletion, acetate treatment and high $\mathrm{pH} .^{7,8}$ When this blockage occurs on the second photon absorption a characteristic $\mathrm{S}_{2} \mathrm{Y}_{\mathrm{Z}}{ }^{\bullet}$ EPR split signal arises from the interaction of the $S=1 / 2 \mathrm{Y}_{\mathrm{z}}$ radical with the $\mathrm{S}=1 / 2$ spin state $\mathrm{S}_{2}$. Another closed cubane form, $S=5 / 2$ of the OEC has been associated with near infra-red induced $\mathrm{S}_{2} \mathrm{Y}_{\mathrm{Z}}{ }^{\bullet}$ split signals. ${ }^{5,10}$ EPR studies of the split signal states have shown that the tyrosyl radical and the OEC weakly interact and that each $\mathrm{S}_{\mathrm{n}} \mathrm{Y}_{\mathrm{Z}}{ }^{\bullet}$ state has a characteristic lineshape in the EPR spectra. ${ }^{9,11}$ These metallo-radical split signal states offer insights into the concerted changes that occur during $S_{\mathrm{n}}$ state transitions. ${ }^{12}$ This is particularly important for the crucial $\mathrm{S}_{2}$ to $\mathrm{S}_{3}$ step where the catalyst is prepared for the O-O bond formation reaction. This transition is believed to involve a number of intermediate stages involving water binding and deprotonation. $^{13,14}$ 


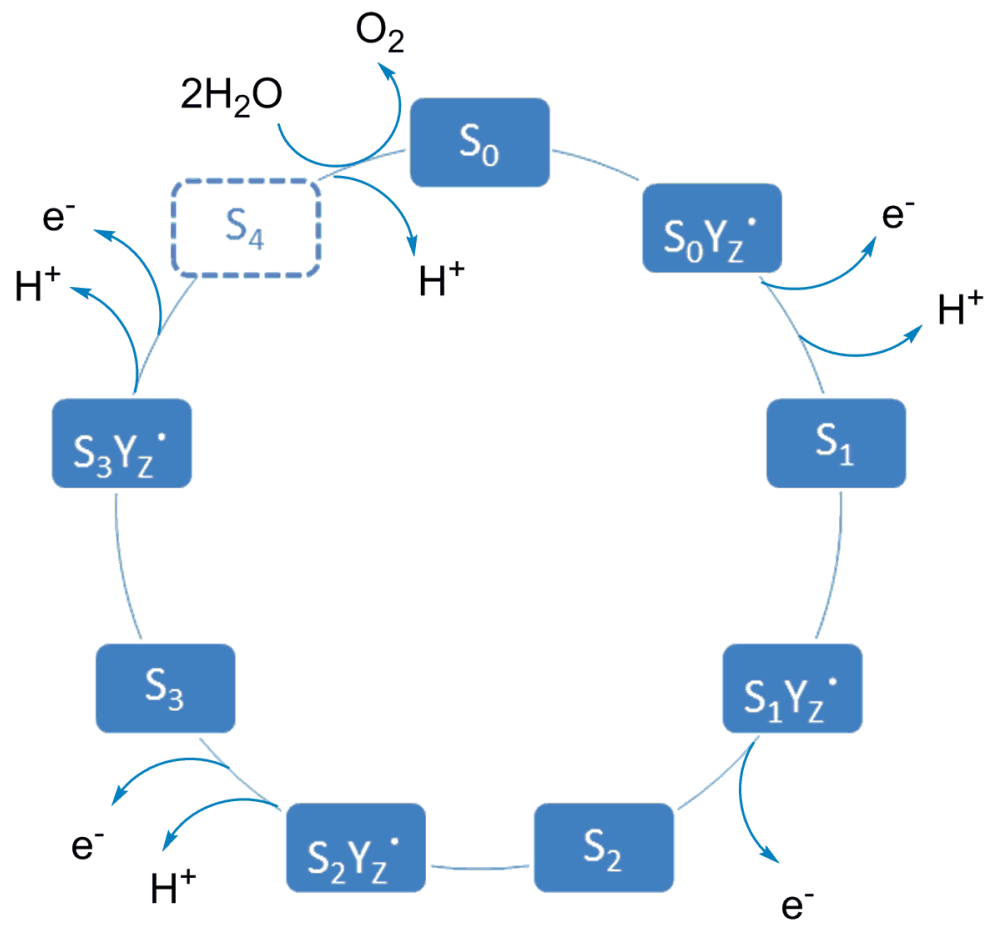

Figure 1 The S-state cycle of the OEC illustrating the sequence of electron and proton releases required to oxidise two water molecules to molecular oxygen and four protons.

While there have been extensive efforts to provide a robust understanding of the $\mathrm{S}_{2}$ state, the $S_{3}$ state is one of the least well understood. Recent attempts to rectify this situation have led to the investigation of the $S_{3}$ state using high resolution EPR techniques, which was interpreted as evidence for a $\left(\mathrm{Mn}^{\mathrm{IV}}\right)_{4}$ oxidation state accompanied by hydroxide binding to $\mathrm{Mn}_{\mathrm{D}}{ }^{15}$ In addition X-ray free electron laser (XFEL) studies have been used to directly study the atom-level structure of the $S_{3}$ state. One study supports the addition of an extra oxygen atom ligand to $\mathrm{Mn}_{\mathrm{D}}$ in $\mathrm{S}_{3},{ }^{16}$ while the other study did not find any evidence for this. ${ }^{17}$ A recent assessment of these structures indicates that further refinements may be required before a definitive $S_{3}$ state atomic-level structure can be assigned. ${ }^{18}$ The origin of the second substrate water which may bind during the $S_{2}$ to $S_{3}$ transition is uncertain, with recent FTIR studies proposing a Ca bound water (W3 or W4). ${ }^{19}$ However debate still 
exists in the literature regarding the identity of this substrate water and there are a number of alternative mechanisms based on so-called carousel and pivot mechanisms. ${ }^{20,21}$ In this report the transition from the $S_{2}$ state to the $S_{3}$ state is examined using BS-DFT calculations for both $\mathrm{Ca}$ and $\mathrm{Sr}$ cluster model forms of the OEC. The $\mathrm{S}_{2} \mathrm{Y}_{\mathrm{Z}} \bullet$ intermediate is initially investigated and the EPR parameters of the trapped tyrosyl radical calculated and compared with experimental determinations and other computational reports. The subsequent formation of the $\mathrm{S}_{3}$ state is then investigated and its calculated EPR parameters compared with experimental determinations. A peroxo model based on the XFEL structure by Suga et al ${ }^{16}$ for $\mathrm{S}_{3}$ is also investigated. Sr substitution is shown to introduce small but significant changes in hydrogen bonding at the $\mathrm{S}_{2} \mathrm{Y}_{\mathrm{Z}}^{\bullet}$ state leading to changes in the tyrosyl radical EPR properties. Sr substitution is also shown to inhibit the movement of a proposed second water substrate (W3) in the $S_{2}$ to $S_{3}$ transition providing a possible explanation for the reduced catalytic activity of the $\mathrm{Sr}$ substituted catalyst.

\section{Computational Details}

Calculations were performed using ORCA 3.0.3 using procedures decribed previously. ${ }^{22}$ The geometries of all the models studied in this chapter were optimised in their respective high spin states using the BP86 functional, ${ }^{23,24}$ utilising the zeroth-order regular approximation (ZORA) Hamiltonian to include scalar relativistic effects. ${ }^{25-27}$ ZORA adapted segmented all-electron relativistically contracted (SARC) basis sets were employed for all atoms, ${ }^{28}$ ZORA versions of the def2-SVP basis sets were used for C and $\mathrm{H}$ atoms with ZORA versions of the def2-TZVP basis set used for all other atoms with $\mathrm{f}$ functions removed. ${ }^{29}$ The computational time of the calculations was decreased by invoking the resolution of identity approximation (RI) along with decontracted auxiliary def2-TZVP/J coulomb fitting basis sets. ${ }^{30-32}$ The optimizations also included the third 
generation (D3) semi-empirical van der waals corrections proposed by Grimme. ${ }^{33,34}$ Increased integration grids (grid 4 and grid $\mathrm{x} 4$ in orca convention) and tight SCF convergence criteria were used throughout the calculations. The Heisenberg exchange coupling constants, hyperfine and nuclear quadrupole coupling values were calculated for all atoms of interest using the broken symmetry DFT methodology using the hybrid metaGGA TPSSh functional with the chain of spheres (RIJCOSX) approximation to exact exchange using the same decontracted auxillary basis sets that were used in the geometry optimization steps. ${ }^{35,36}$ Initial broken symmetry guesses were constructed using the 'flipspin' feature of ORCA. ${ }^{37}$ Calculation of the hyperfine and quadrupole tensors used basis sets developed by Neese et al. based on the SARC def2-TZVP for the Mn, $\mathrm{N}$ and $\mathrm{O}$ atoms which contain fully decontracted s-shells with three additional steep primitives added to the core, in addition to this def2-TZVP(-f) was used for all other atoms. ${ }^{32,38}$ The integration grids were increased to an integration accuracy of 11 and 9 for $\mathrm{Mn}, \mathrm{N}$ and $\mathrm{O}$ respectively. Picture change effects were applied for the calculation of hyperfine and nuclear quadrupole tensors. Heisenberg exchange coupling constants and spin projected hyperfine couplings were calculated using the methodology proposed by Pantazis et al. ${ }^{39}$ The calculated ${ }^{55} \mathrm{Mn}$ isotropic hyperfine couplings were scaled with an empirically derived factor of 1.47 to account for well known deficiencies in the DFT description of the Fermi contact term. ${ }^{40,41}$ This factor has been validated for 6 models of mononuclear, dinuclear and tetranuclear manganese complexes (see Table S1 in Supporting Information; structures are shown in Figure S2). The BS-DFT approach and the use of the TPSSh functional in the calculations of Heisenberg exchange coupling constants in manganese systems has been discussed and compared to the performance of other functionals in earlier studies of manganese dimers, trimers and tetrameric systems. ${ }^{38-40,42,43}$ For the calculation of the $\mathbf{g}$ tensor of the $\mathrm{S}_{2} \mathrm{Y}_{\mathrm{Z}}^{\bullet}$ tyrosyl radical, the approach used by Retegan et al. was followed 
where the open shell manganese ions were replaced with diamagnetic ions of the same formal charge $\left(\mathrm{Ga}^{3+}\right.$ and $\left.\mathrm{Ge}^{4+}\right) \cdot{ }^{44}$ Convergence to the correct BS and HS states in all calculations was confirmed by examination of the calculated Mulliken spin populations.

\section{Model Systems}

Most of the starting models for the calculations (Figure S1) were first geometry optimised in the $S_{2}$ and $S_{2} Y_{Z^{\bullet}}$ states. The terminal carbon atom on each chain was constrained at the starting coordinates. The starting models were generated from the crystal structure determinations, PDB ID: 4UB6 (Ca), PDB ID: 4IL6 (Sr). The exception to this was the $\mathrm{S}_{3}$-peroxo model where the starting coordinates prior to geometry optimisation were taken from the $\mathrm{S}_{3}$ XFEL coordinates, 5WS6. The high valent oxidation state scheme $\left(\mathrm{Mn}^{\mathrm{III}}\right)$ $\left(\mathrm{Mn}^{\mathrm{IV}}\right)_{3}$ was adopted for all $\mathrm{S}_{2}$ models. All the OEC cluster models studied contain the seven directly coordinated amino acid residues (all found in the D1 protein chain unless otherwise indicated): Asp-170, Glu-189, His-332, Glu-333, Asp-342, Ala-344 and CP43Glu-354. Two fully protonated water molecules W3 and W4 coordinated to the calcium/strontium ion were also included as well as a water molecule $\mathrm{W} 1$ and hydroxide group W2 coordinated to $\mathrm{Mn}_{\mathrm{A}}$. As well as this the models include the important second sphere residues: Asp-61, Tyr-161, Gln-165, His-190, Asn-298, His-337 and CP43-Arg357. In addition to this twelve closely associated crystallographic water molecules as well as partial backbone of Glu-329 was involved, having previously been found to hydrogen bond with His-332. Inclusion of Tyr-161( $\left.\mathrm{Y}_{\mathrm{Z}}\right)$ and its hydrogen bonding partner His-190 is essential for all S-state models models. All bridging oxygens were in the oxo form and the terminal W2 ligand on $\mathrm{Mn}_{\mathrm{A}}$ was an hydroxo ligand with $\mathrm{W} 1$, W3 and $\mathrm{W} 4$ being aquo ligands. An additional label is used to distinguish between the open cubane $(\mathbf{O})$ and closed 
cubane $(\mathbf{C})$ forms of the OEC. The numbering scheme for the tyrosyl radicals investigated in the $\mathrm{S}_{2} \mathrm{Y}_{\mathrm{Z}}^{\bullet}$ state is shown below in Figure 2.

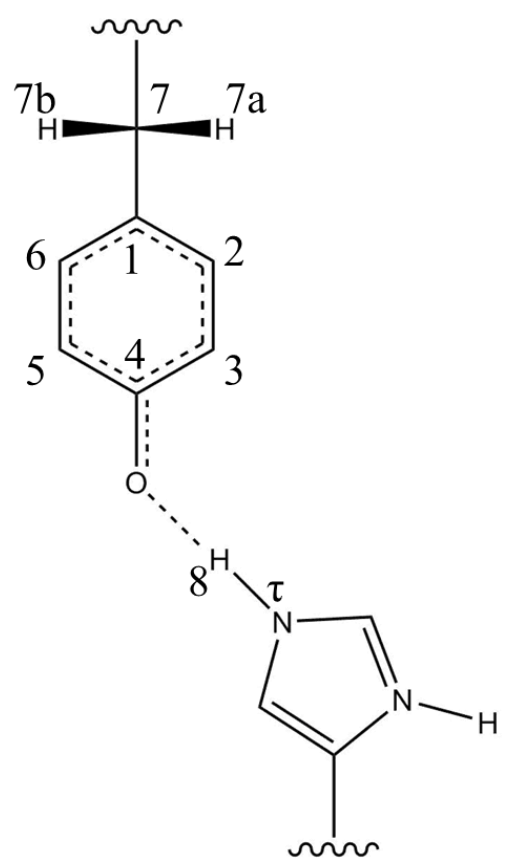

Figure 2. Numbering scheme for the atoms of interest in the $\mathrm{Y}_{\mathrm{Z}} \bullet$ tyrosyl radical.

The numbering scheme for the OEC is shown in Figure 3. When discussing some $\mathrm{S}_{3}$ models a third label is used to distinguish the identity of the extra water, $\mathrm{W}_{\mathrm{x}}$. This labelling scheme will be discussed further in the relevant results section. 


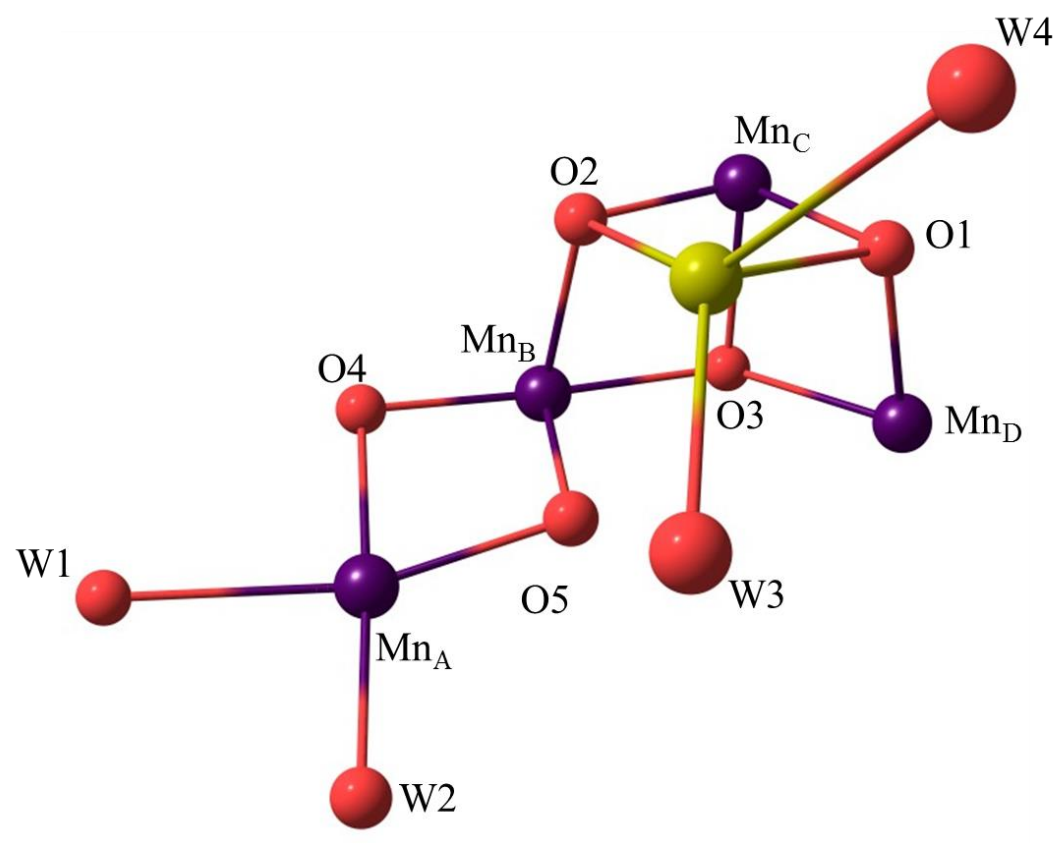

Figure 3. Numbering scheme for the constructed cluster models of the OEC. Colour coding: manganese (purple), oxygen (red), nitrogen (blue), carbon (grey). Hydrogen atoms omitted for clarity

\section{Results and Discussion}

Results will first be presented for the $\mathrm{S}_{2}$ and $\mathrm{S}_{2} \mathrm{Y}_{\mathrm{Z}}^{\bullet}$ models arising from open cubane and closed cubane $\mathrm{Ca}$ and $\mathrm{Sr}$ models. Discussion will first focus on the structural changes that occur in the cluster models upon oxidation of the tyrosine residue. In addition the Heisenberg exchange coupling constants for these models will also be discussed before turning to the calculated EPR parameters. Following on from this discussion will then move to the $\mathrm{S}_{3}$ state beginning firstly with a presentation of the structures before considering the exchange coupling constants and ${ }^{55} \mathrm{Mn}$ hyperfine couplings calculated for all the models studied. 
The $\mathrm{S}_{2}$ and $\mathrm{S}_{2} \mathrm{Y}_{\mathrm{Z}}^{\bullet}$ States

\section{Geometry}

Analysis of the Mulliken spin populations (values close to 4.0 and 3.0 for Mn(III) and Mn (IV) respectively) for all the calculated models studied in this section show that the oxidation states of the manganese ions in $\mathrm{S}_{2} \mathrm{Y}_{Z^{\bullet}}$ remain essentially unchanged from $\mathrm{S}_{2}$. As a result of this, the changes in the interatomic distances of the OEC upon oxidation of the $\mathrm{Y}_{\mathrm{Z}}$ residue are minor. Figure 4 shows the local environment of the $\mathrm{Y}_{\mathrm{Z}}$ residue both before and after the oxidation of the $\mathrm{Y}_{\mathrm{Z}}$ residue. The area surrounding the $\mathrm{Y}_{\mathrm{Z}}$ residue changes upon formation of the tyrosyl radical. In all models it was found that the tyrosine residue is deprotonated with the proton moving spontaneously to the $\mathrm{N}_{\tau}$ atom of the imidazole ring of the His-190 residue in line with the fast proton coupled electron transfer (PCET) mechanism suggested for $\mathrm{Y}_{Z}$ oxidation. ${ }^{45-47}$ The observed proton shift indicates that the tyrosyl residue in the $\mathrm{S}_{2} \mathrm{Y}_{\mathrm{Z}}^{\bullet}$ form can be described as a neutral radical which is coupled to an imidazolium cation. From Figure 4 it can be seen that a significant difference between the calcium and strontium models is the $\mathrm{Ca} / \mathrm{Sr}-\mathrm{W} 3$ and $\mathrm{Ca} / \mathrm{Sr}-\mathrm{W} 4$ distances which were found to be $0.2 \AA$ longer in the strontium models. As a result of the W3 and W4 bond length differences the hydrogen-bonding environment of the tyrosine residue is also altered (ca. $0.03 \AA$ difference in water-tyrosine hydrogen bonds) following strontium substitution. The hydrogen bonding network of the $\mathrm{Y}_{\mathrm{Z}}$ residue is thought to be optimised to ensure proper function and even relatively minor perturbations in the network have been thought to significantly impact its operation. ${ }^{48,49}$ It has been suggested that one of the potential roles for the calcium ion in the OEC is regulate the electronic structure and the redox potential of the $\mathrm{Y}_{\mathrm{Z}}$ residue. ${ }^{50}$ However recent work by Krewald et al. investigating the redox potential of the $Y_{Z}$ residue in a number of calcium substituted $S_{n}$ state transitions has 
shown that the cofactors on the donor side of PSII are only sensitive to the charge of the cation and as such they ruled out this potential role. ${ }^{51}$ It should be noted however that Krewald et al. found that the OEC can respond to calcium substitution with a rearrangement of the hydrogen bonding waters (comparable with the perturbations observed here) suggesting that calcium may play a role in ordering the hydrogen bond network of the $\mathrm{Y}_{\mathrm{Z}}$ residue and the OEC. ${ }^{52-54} \mathrm{QM} / \mathrm{MM}$ calculations by Nakamura et al. found a substantial rearrangement of the hydrogen bond network following tyrosine oxidation and observed a novel proton transfer mechanism where the histidine proton is transferred to a nearby water. ${ }^{55}$ In all of the models studied here no rearrangement of the hydrogen bond network similar to that seen by Nakamura et al. was observed and the histidine was not deprotonated by a water molecule. 


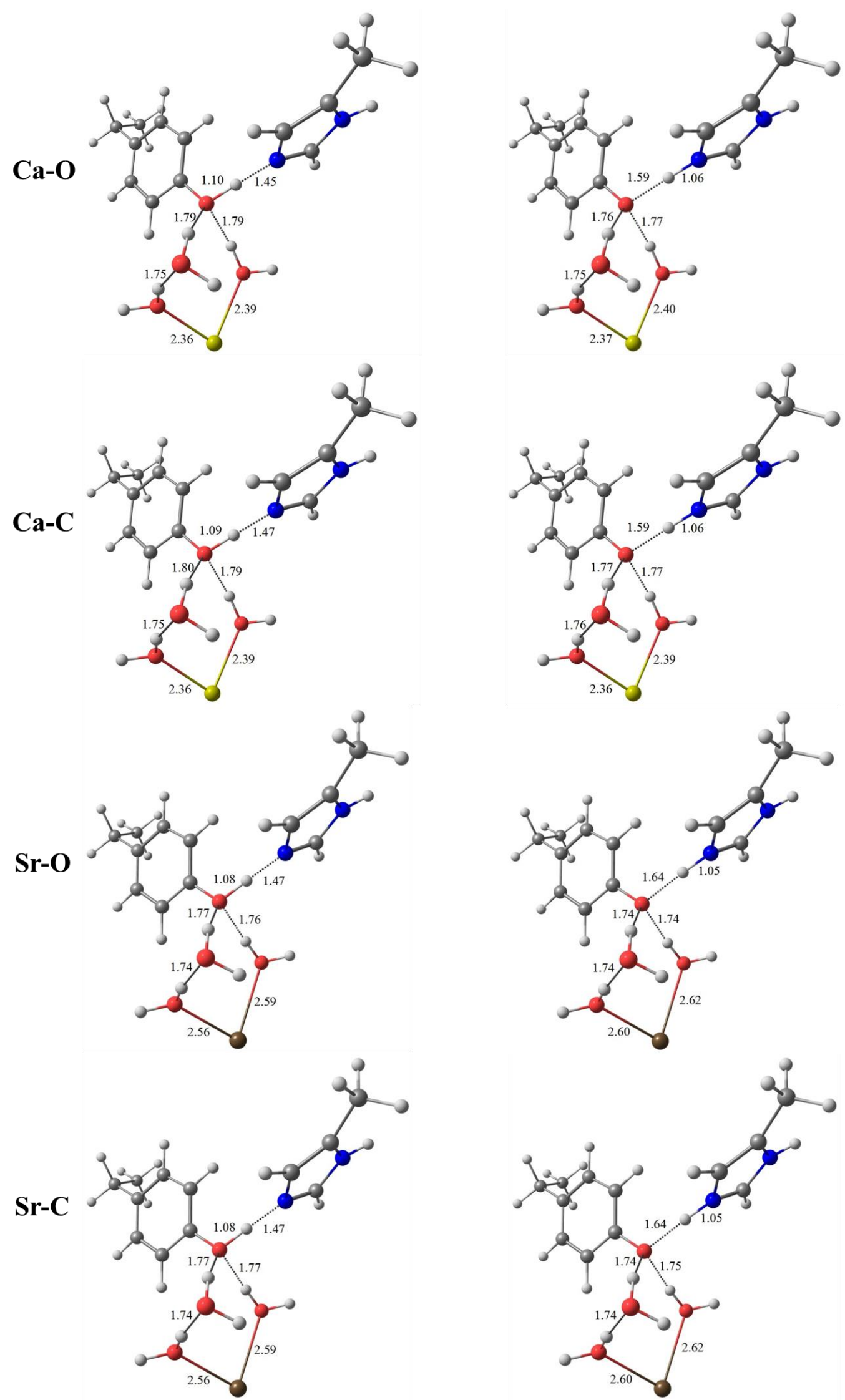

Figure 4. The hydrogen bonding environment of the $\mathrm{Yz}$ residue in the $\mathrm{S}_{2}$ state (left) and $\mathrm{S}_{2} \mathrm{Y}_{\mathrm{Z}} \bullet$ state (right) for all models studied, bond lengths shown in Å. Colour coding: calcium (yellow), strontium (brown), oxygen (red), carbon (grey), nitrogen (blue) and hydrogen (white). 


\section{Heisenberg Exchange Coupling Constants}

Insight into the magnetic behaviour of $\mathrm{S}_{2}$ and $\mathrm{S}_{2} \mathrm{Y}_{\mathrm{Z}} \bullet$ can be provided by the exchange coupling constants between the manganese ions. ${ }^{39}$ Diagonalising the Heisenberg Hamiltonian leads to the complete spectrum of spin energy levels. Figure 5 shows the calculated Heisenberg exchange coupling constants as well as the first two spin states and the energy difference between them. In the open cubane $\mathrm{S}_{2} \mathrm{Y}_{\mathrm{Z}}^{\bullet}$ models studied there are two antiferromagnetic interactions between $\mathrm{Mn}_{\mathrm{A}}-\mathrm{Mn}_{\mathrm{B}}$ and $\mathrm{Mn}_{\mathrm{C}}-\mathrm{Mn}_{\mathrm{D}}$ with a ferromagnetic interaction found between $\mathrm{Mn}_{\mathrm{B}}-\mathrm{Mn}_{\mathrm{C}}$. In the closed cubane $\mathrm{S}_{2} \mathrm{Y}_{\mathrm{Z}}^{\bullet}$ cluster models all the exchange interactions between the three $\mathrm{Mn}^{\mathrm{IV}}$ ions which make up the closed cubane unit are ferromagnetic, with the interaction between $\mathrm{Mn}_{\mathrm{A}}-\mathrm{Mn}_{\mathrm{B}}$ antiferromagnetic. As a result of the minor structural perturbations found in the OEC structure following $\mathrm{Y}_{\mathrm{Z}}$ oxidation, the Heisenberg exchange coupling constants and coupling topology for all models are essentially similar to those calculated for the corresponding $S_{2}$ models. Additionally Figure 5 shows that the $\mathrm{S}_{2} \mathrm{Y}_{\mathrm{Z}}^{\bullet}$ models have the same $\mathrm{S}=1 / 2$ (open) and $\mathrm{S}=5 / 2$ (closed) OEC ground state spin found in the corresponding $S_{2}$ state form with a similar energy gap to the first excited state. 


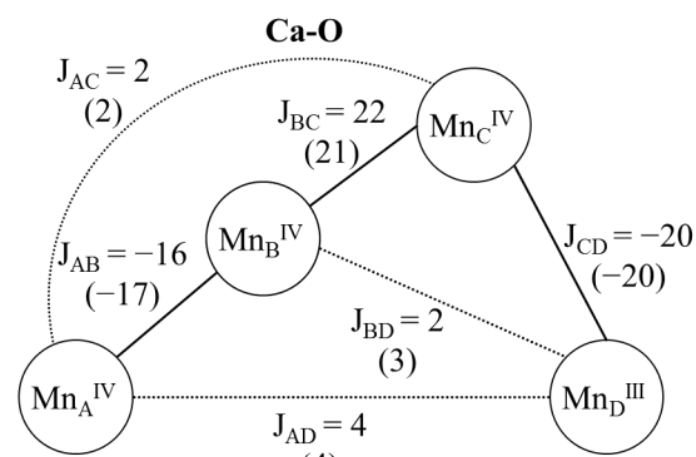

$$
\begin{gathered}
\mathrm{S}_{\mathrm{t}}(\mathrm{GS})=1 / 2^{(4)} \mathrm{S}_{\mathrm{t}}(\mathrm{ES})=3 / 2 \\
\Delta \mathrm{E}_{\mathrm{ES}-\mathrm{GS}}=27
\end{gathered}
$$

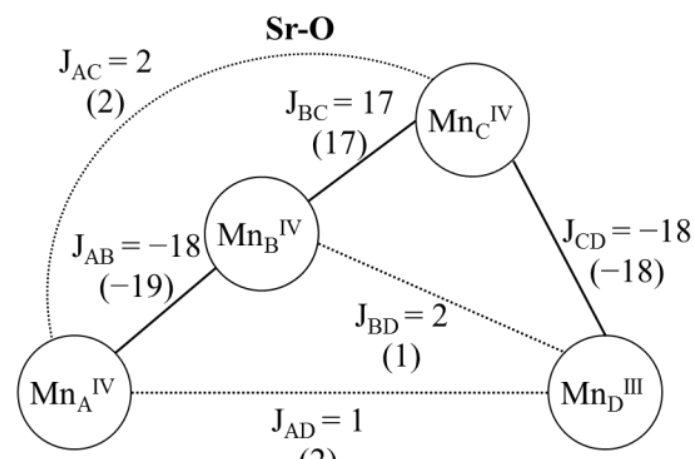

$$
\begin{gathered}
\mathrm{S}_{\mathrm{t}}(\mathrm{GS})=1 / 2{ }^{(2)} \mathrm{S}_{\mathrm{t}}(\mathrm{ES})=3 / 2 \\
\Delta \mathrm{E}_{\mathrm{ES}-\mathrm{GS}}=27
\end{gathered}
$$

(28)

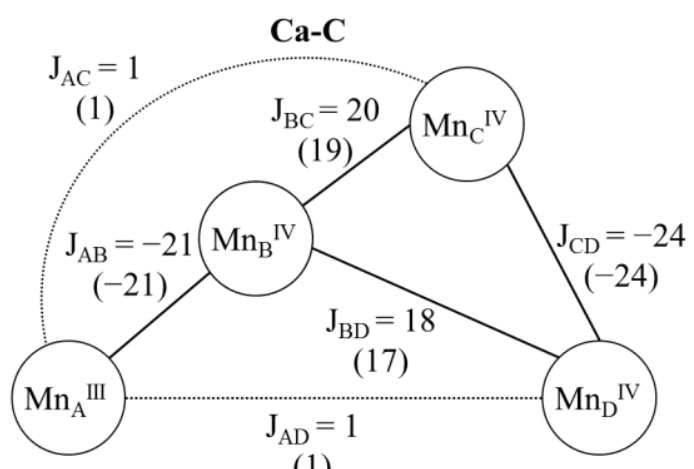

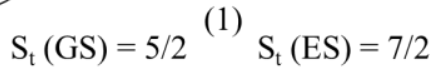$$
\Delta \mathrm{E}_{\mathrm{ES}-\mathrm{GS}}=32
$$

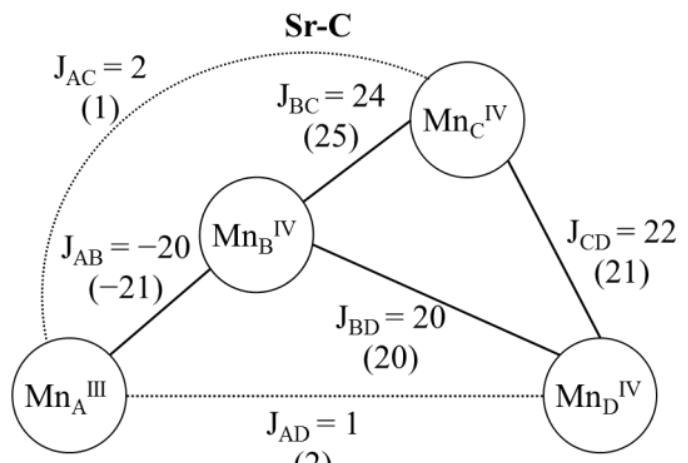

$$
\begin{gathered}
\mathrm{S}_{\mathrm{t}}(\mathrm{GS})=5 / 2{ }^{(2)} \mathrm{S}_{\mathrm{t}}(\mathrm{ES})=7 / 2 \\
\Delta \mathrm{E}_{\mathrm{ES}-\mathrm{GS}}=29
\end{gathered}
$$

(31)

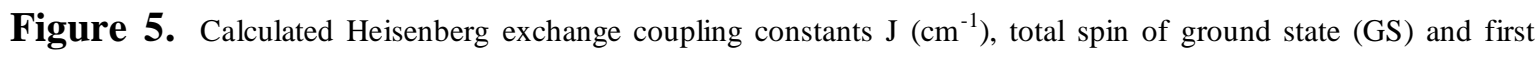
excited state (ES) as well as the energetic separation between the two lowest energy levels $\left(\mathrm{cm}^{-1}\right)$ of the $\mathrm{Mn}_{4} \mathrm{CaO}_{5}$ cluster in the open cubane and closed cubane forms in the calcium/strontium $\mathrm{S}_{2} \mathrm{Y}_{\mathrm{Z}} \bullet$ state. Values in brackets refer to the $\mathrm{S}_{2}$ state.

\section{${ }^{55} \mathrm{Mn}$ Hyperfine Couplings}

Table 1 shows that there is little change in the calculated ${ }^{55} \mathrm{Mn}$ hyperfine couplings of the OEC between the $\mathrm{S}_{2} \mathrm{Y}_{\mathrm{Z}} \bullet^{\bullet}$ and $\mathrm{S}_{2}$ states. These results, in conjunction with those discussed previously would indicate that the electronic structure of the Mn OEC in the $\mathrm{S}_{2}$ state is unchanged on $\mathrm{Y}_{\mathrm{Z}}$ oxidation. 
Table 1. Calculated Spin Projected ${ }^{55} \mathrm{Mn}$ hyperfine couplings (in $\mathrm{MHz}$ ) for the $\mathrm{S}_{2} \mathrm{Y}_{\mathrm{Z}} \bullet$ models in both the open and closed forms.

\begin{tabular}{cccccc}
\hline Model & & $A_{\text {iso }}$ & $T_{1}$ & $T_{2}$ & $T_{3}$ \\
\hline \multirow{4}{*}{ Ca-O } & $\mathrm{Mn}_{\mathrm{A}}$ & $-293(-287)$ & $-28(-30)$ & $5(7)$ & $23(23)$ \\
& $\mathrm{Mn}_{\mathrm{B}}$ & $204(198)$ & $-5(-8)$ & $-1(-1)$ & $6(10)$ \\
& $\mathrm{Mn}_{\mathrm{C}}$ & $224(224)$ & $-7(-5)$ & $-1(-1)$ & $8(6)$ \\
& $\mathrm{Mn}_{\mathrm{D}}$ & $-258(-253)$ & $-51(-51)$ & $-42(-45)$ & $93(96)$ \\
\hline \multirow{4}{*}{ Ca-C } & $\mathrm{Mn}_{\mathrm{A}}$ & $119(113)$ & $-21(-27)$ & $0(0)$ & $21(27)$ \\
& $\mathrm{Mn}_{\mathrm{B}}$ & $-76(-71)$ & $-6(-6)$ & $2(3)$ & $4(3)$ \\
& $\mathrm{Mn}_{\mathrm{C}}$ & $-91(-90)$ & $-3(-2)$ & $-2(-2)$ & $5(4)$ \\
& $\mathrm{Mn}_{\mathrm{D}}$ & $-90(-87)$ & $-2(-2)$ & $-1(1)$ & $3(3)$ \\
\hline \multirow{4}{*}{ Sr-OO } & $\mathrm{Mn}_{\mathrm{A}}$ & $-297(-289)$ & $-13(-10)$ & $1(0)$ & $12(10)$ \\
& $\mathrm{Mn}_{\mathrm{B}}$ & $199(195)$ & $-6(-6)$ & $-3(-2)$ & $9(8)$ \\
& $\mathrm{Mn}_{\mathrm{C}}$ & $235(234)$ & $-7(-5)$ & $-2(-2)$ & $9(8)$ \\
& $\mathrm{Mn}_{\mathrm{D}}$ & $-257(-253)$ & $-57(-58)$ & $-39(-36)$ & $96(93)$ \\
\hline \multirow{4}{*}{ Sr-C } & $\mathrm{Mn}_{\mathrm{A}}$ & $117(112)$ & $-25(-31)$ & $0(0)$ & $25(31)$ \\
& $\mathrm{Mn}_{\mathrm{B}}$ & $-78(-74)$ & $-5(-6)$ & $2(3)$ & $3(3)$ \\
& $\mathrm{Mn}_{\mathrm{C}}$ & $-89(-87)$ & $-3(-2)$ & $-1(-2)$ & $4(4)$ \\
& $\mathrm{Mn}_{\mathrm{D}}$ & $-84(-80)$ & $-4(-5)$ & $1(1)$ & $4(4)$ \\
\hline
\end{tabular}

$\mathrm{T}_{\mathrm{i}}$ represents the traceless form of the full tensor. Values in brackets are for the corresponding $\mathrm{S}_{2}$ state models.

\section{$\mathrm{Y}_{\mathrm{Z}}^{\ominus} \mathrm{g}$-Tensor}

We now investigate in detail the calculated EPR parameters of the tyrosyl radical formed in the $\mathrm{S}_{2} \mathrm{Y}_{\mathrm{Z}} \bullet$ state. Initial studies of tyrosyl radicals employed simplified models such as the phenoxyl-water or phenoxyl-imidazolium pairs to investigate the structural and spectroscopic properties of these organic radicals. ${ }^{56-59}$ In recent years more elaborate models have been constructed which also contain residues that surround the tyrosyl radical in order to study the histidine-tyrosine pair in both the $\mathrm{Y}_{\mathrm{Z}}$ and $\mathrm{Y}_{\mathrm{D}}$ residues. ${ }^{46,49,60,61}$ As well as considering the effects of the protein on the structure and spectroscopic properties, the larger models have also allowed the protein environment of the two redox active tyrosine residues found in PSII to be distinguished. Table 2 shows calculated g-tensors for all the $\mathrm{S}_{2} \mathrm{Y}_{\mathrm{Z}^{\bullet}}$ models studied with Figure 6 showing the orientations of the calculated $\mathrm{g}$-tensor. 
Table 2. Calculated effective g-tensors for the tyrosyl radical found in all the investigated models of the $\mathrm{S}_{2} \mathrm{Y}_{\mathrm{Z}}^{\bullet}$ state

\begin{tabular}{cccccc}
\hline & Ca-O & Ca-C & Sr-O & Sr-C & Exp. $^{62}$ \\
\hline$g_{\text {iso }}$ & 2.00420 & 2.00420 & 2.00462 & 2.00462 & 2.00443 \\
$g_{\text {x }}$ & 2.00622 & 2.00621 & 2.00749 & 2.00748 & 2.00689 \\
$g_{\mathrm{y}}$ & 2.00421 & 2.00420 & 2.00420 & 2.00420 & 2.00418 \\
$g_{\mathrm{z}}$ & 2.00218 & 2.00218 & 2.00219 & 2.00219 & 2.00221 \\
\hline
\end{tabular}

The experimental results of Ioannidis et al. are for the $\mathrm{Y}_{\mathrm{Z}}$ radical in the native OEC.

From Figure 6 it can be seen that the orientations of the calculated g-tensors is in agreement with earlier model systems. ${ }^{63}$ In all models the $g_{\mathrm{x}}$ axis is found to be oriented along the $\mathrm{C}-\mathrm{O}$ bond with $g_{\mathrm{z}}$ perpendicular to the plane of the ring and $g_{\mathrm{y}}$ in the tyrosine ring plane. Commonly EPR studies of the tyrosyl radical have been performed by selectively replacing the $\mathrm{Y}_{\mathrm{D}}$ residue with phenylalanine and removing the tetranuclear $\mathrm{Mn}$
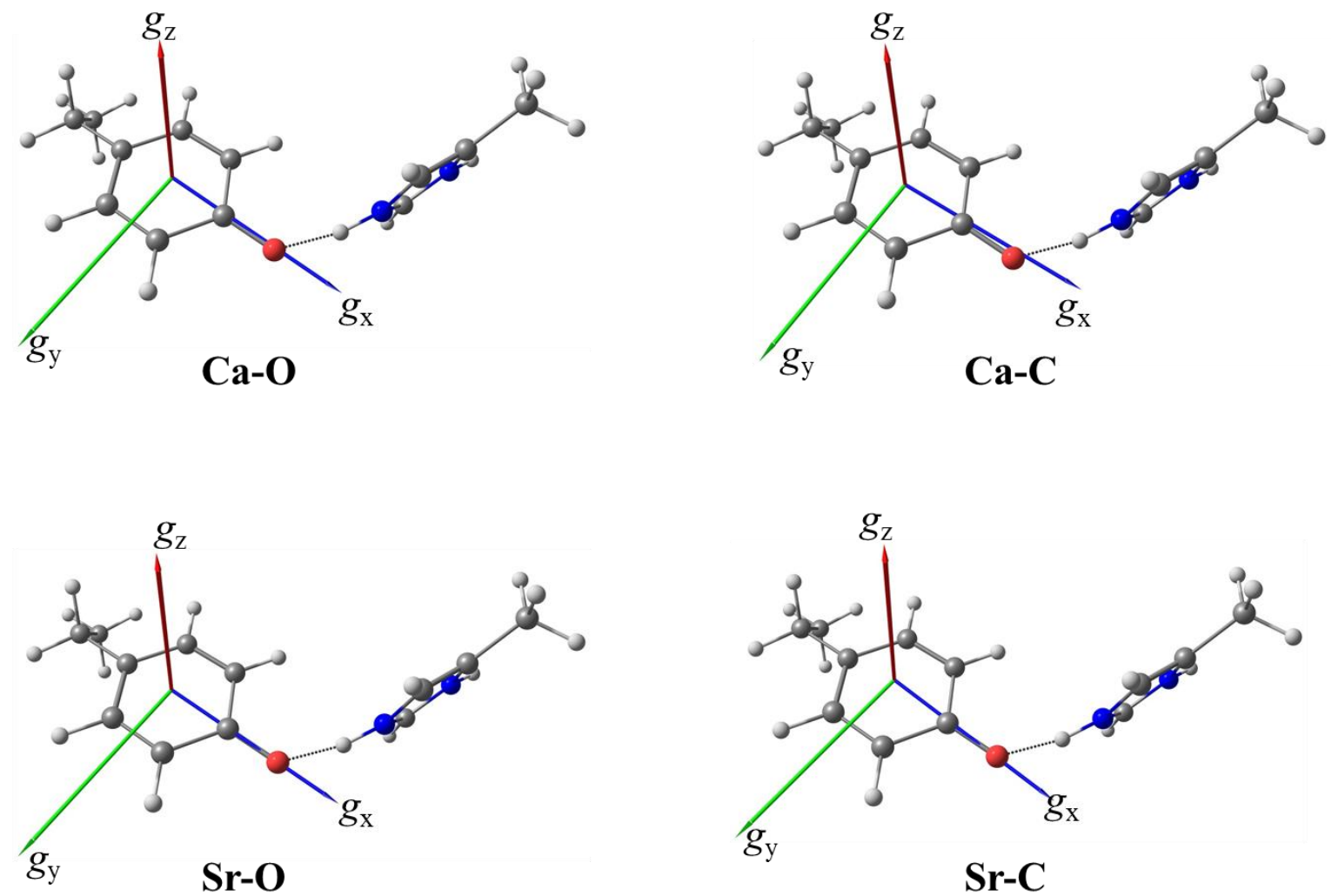

Figure 6. The orientation of the calculated $\mathbf{g}$-tensors for the tyrosyl radical in all the investigated models of the $\mathbf{S}_{\mathbf{2}} \mathbf{Y}_{\mathbf{Z}} \bullet$ state 
cluster. ${ }^{64,65}$ Ioannidis et al. have however studied the $\mathrm{Y}_{\mathrm{Z}}^{\bullet}$ radical in the presence of the Mn OEC. ${ }^{62}$ Table 2 shows a difference in the calculated $g_{\mathrm{x}}$ values between the $\mathbf{C a}$ and $\mathbf{S r}$ models. For the $g_{\mathrm{y}}$ and $g_{\mathrm{z}}$ components no such differences can be observed. Previous studies of the tyrosyl radical have shown that the $g_{\mathrm{x}}$ component is strongly dependent on the hydrogen bond length between the tyrosyl radical and the imidazolium cation. ${ }^{44,59}$ In this work a similar dependence is observed with the longer hydrogen bond (1.64 $\AA$ ) for Sr$\mathbf{O}$ and $\mathbf{S r}-\mathbf{C}$ yielding the larger calculated $g_{\mathrm{x}}$ value, while the shorter hydrogen bond length for the Ca models $(1.59 \AA)$ leads to a reduced $g_{x}$ component. The g-tensor components in the absence of the Mn OEC have been measured by Matsuoka et al. who reported $g_{\mathrm{x}}=$ 2.00714 in frozen solution and 2.00705 in single crystals. ${ }^{59}$ These values of $g_{\mathrm{x}}$ were found to be comparable to values reported for the more widely studied $\mathrm{Y}_{\mathrm{D}}^{\bullet}$ of PSII, where a range of $g_{\mathrm{x}}$ values for $\mathrm{Y}_{\mathrm{D}}^{\bullet}$ in various organisms from 2.0074 to 2.0078 have been reported. ${ }^{66}$ The $g_{\mathrm{x}}$ component is known to strongly depend on the hydrogen bonding and the electrostatic environment surrounding the tyrosyl radical. An example of this effect is the tyrosyl radical $\mathrm{Y}_{122}{ }^{\bullet}$ of Escherichia coli ribonucleotide reductase where the $g_{\mathrm{x}}$ value increases significantly with removal of hydrogen bonding. ${ }^{57,67,68}$ The better agreement for the native Ca models with the experimental results of Ioannidis et al. for samples retaining the OEC compared with the Mn depleted OEC studies by Matsuoka et al., is encouraging. These comparisons also suggest that the removal of the Mn OEC alters the waters surrounding the tyrosine residue, reducing their hydrogen bonding capability. ${ }^{59,62}$

The Mulliken spin populations of the tyrosyl fragments are shown in Figure 7. As has previously been reported for a series of phenoxyl radical model systems, ${ }^{69}$ the trend seen in the $g_{x}$ components shown in Table 2 follows closely the changes observed in the unpaired spin population of the tyrosyl oxygen atom. Previous studies of the $\mathrm{Y}_{\mathrm{Z}}^{\bullet}$ system have found 
a linear correlation between the oxygen unpaired spin population and the $g_{\mathrm{x}}$ component. ${ }^{44,59}$ As seen in Figure 4, on going from the $\mathbf{C a ~} \mathrm{S}_{2} \mathrm{Y}_{\mathrm{Z}} \bullet$ models to the Sr models, the hydrogen bond length between the neutral tyrosine and the imidazolium cation increases from $1.59 \AA$ to $1.64 \AA$, this creates a weaker hydrogen bond to the $\mathrm{Y}_{\mathrm{Z}}^{\bullet}$ radical in the strontium models leading to an increased spin population at the carbonyl oxygen. Similar behaviour has been observed in the hydrogen bonding environment of semiquinone radicals and for the primary quinone $\left(\mathrm{Q}_{\mathrm{A}} / \mathrm{Q}_{\mathrm{A}}{ }^{\bullet}\right)$ found in bacterial reaction centres. ${ }^{70,71}$

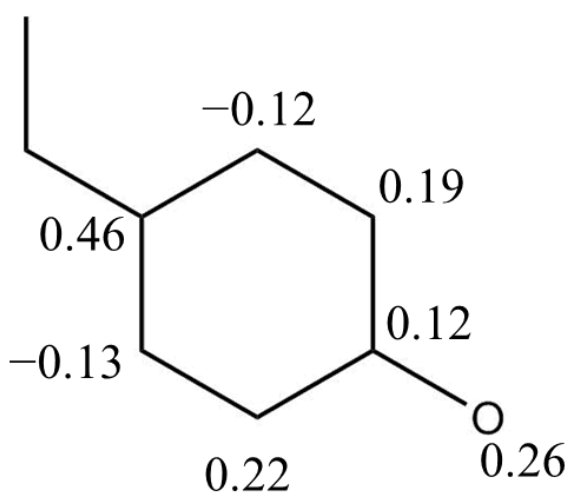

Ca-O

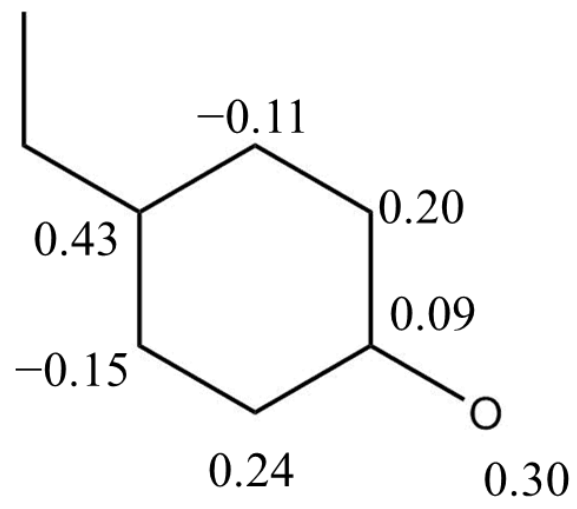

Sr-O

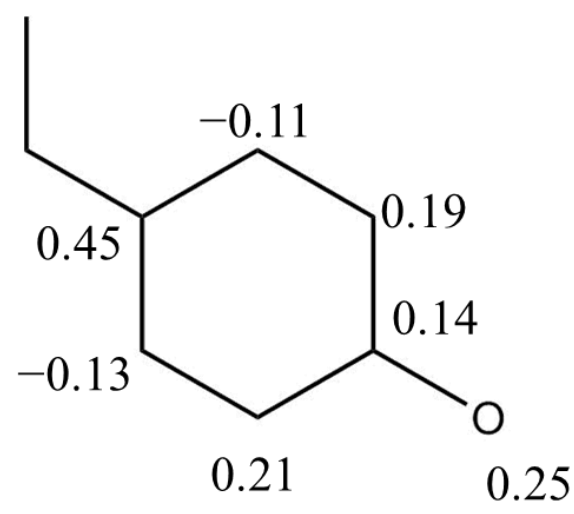

Ca-C

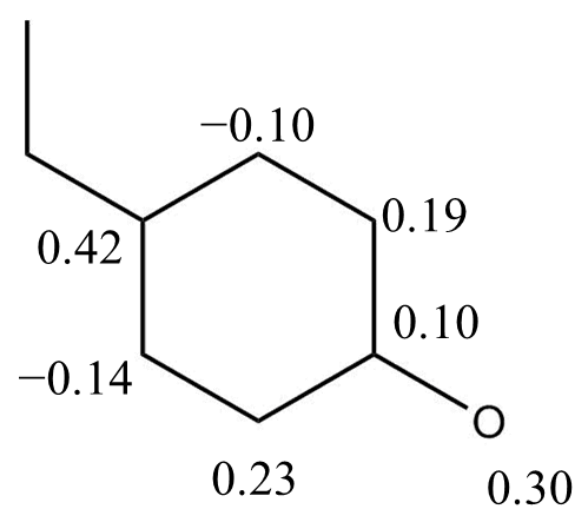

Sr-C

Figure 7. Mulliken spin populations of the tyrosyl radical fragment in the open and closed forms of native and strontium substituted $\mathrm{S}_{2} \mathrm{Y}_{\mathrm{Z}} \bullet$ state. 
$\mathrm{Y}_{\mathrm{Z}} \bullet{ }^{1} \mathrm{H}$ hyperfine couplings.

Insight into the electronic structure of the tyrosine radical may also be gained by studying the hyperfine couplings of the spin active nuclei which comprise the radical. Table 3 shows the calculated ${ }^{1} \mathrm{H}$ hyperfine couplings (HFCs) for the tyrosyl radical protons in all the investigated $\mathrm{S}_{2} \mathrm{Y}_{Z^{\bullet}}$ models. In addition Table 3 shows experimental values and assignments obtained from 2D-HYSCORE experiments performed by Nakazawa et al. on the green alga Chlamydomonas reinhardtii. ${ }^{72}$

Table 3. Calculated ${ }^{1} \mathrm{H}$ hyperfine couplings (in $\mathrm{MHz}$ ) for $\mathrm{S}_{2} \mathrm{Y}_{\mathrm{Z}^{\bullet}}$ in both the open and closed forms and comparison with available experimental data.

\begin{tabular}{|c|c|c|c|c|c|}
\hline & Label & $A_{\text {iso }}$ & $T_{1}$ & $T_{2}$ & $T_{3}$ \\
\hline \multirow{7}{*}{ Ca-O } & $\mathrm{H} 2$ & 3.9 & -3.6 & 0.6 & 3.0 \\
\hline & H3 & -17.3 & -6.4 & -2.3 & 8.7 \\
\hline & H5 & -17.5 & -6.8 & -2.5 & 9.2 \\
\hline & H6 & 4.1 & -3.6 & 0.5 & 3.1 \\
\hline & $\mathrm{H} 7 \mathrm{a}$ & 31.6 & -2.6 & -2.2 & 4.8 \\
\hline & $\mathrm{H} 7 \mathrm{~b}$ & 4.4 & -1.1 & -1.0 & 2.1 \\
\hline & H8 & 0.2 & -4.1 & -3.9 & 8.0 \\
\hline \multirow{7}{*}{ Ca-C } & $\mathrm{H} 2$ & 3.9 & -3.4 & 0.4 & 3.1 \\
\hline & H3 & -17.4 & -6.1 & -2.7 & 8.8 \\
\hline & H5 & -17.9 & -6.6 & -2.5 & 9.1 \\
\hline & H6 & 4.0 & -3.5 & 0.3 & 3.1 \\
\hline & $\mathrm{H} 7 \mathrm{a}$ & 30.5 & -2.3 & -2.1 & 4.3 \\
\hline & $\mathrm{H} 7 \mathrm{~b}$ & 5.9 & -1.1 & -0.9 & 2.0 \\
\hline & H8 & 0.2 & -4.1 & -4.1 & 8.1 \\
\hline \multirow{7}{*}{ Sr-O } & $\mathrm{H} 2$ & 4.2 & -3.6 & 0.5 & 3.1 \\
\hline & H3 & -17.2 & -6.4 & -2.4 & 8.8 \\
\hline & H5 & -17.7 & -6.4 & -2.5 & 8.9 \\
\hline & H6 & 4.6 & -3.6 & 0.4 & 4.0 \\
\hline & $\mathrm{H} 7 \mathrm{a}$ & 31.4 & -2.6 & -1.1 & 3.7 \\
\hline & $\mathrm{H} 7 \mathrm{~b}$ & 4.9 & -1.2 & -0.9 & 2.1 \\
\hline & $\mathrm{H} 8$ & 0.1 & -4.3 & -4.0 & 8.3 \\
\hline \multirow{7}{*}{ Sr-C } & $\mathrm{H} 2$ & 4.1 & -3.4 & 0.4 & 3.1 \\
\hline & H3 & -17.1 & -6.2 & -2.4 & 8.6 \\
\hline & H5 & -17.6 & -6.1 & -2.4 & 8.5 \\
\hline & H6 & 4.4 & -3.4 & 0.3 & 3.2 \\
\hline & $\mathrm{H} 7 \mathrm{a}$ & 31.1 & -2.5 & -1.2 & 3.6 \\
\hline & $\mathrm{H} 7 \mathrm{~b}$ & 5.2 & -1.1 & -0.8 & 2.0 \\
\hline & H8 & 0.1 & -4.2 & -3.9 & 8.2 \\
\hline
\end{tabular}




\begin{tabular}{cccccc}
\hline & H2/H6 & 4.8 & -0.9 & -0.9 & 1.8 \\
& H3/H5 & -18.7 & -6.1 & -4.1 & 10.2 \\
Exp. $^{72}$ & H7a & 30.2 & -2.2 & -2.2 & 4.3 \\
& H7b & 4.8 & -0.9 & -0.9 & 1.8 \\
& H8 & - & - & - & - \\
\hline
\end{tabular}

Similar experimental values have also been reported by Tommos et al. although there is disagreement for the reported anisotropic hyperfine couplings of the $\mathrm{H} 2$ and $\mathrm{H} 6$ protons (see main text). ${ }^{73}$

The data contained in Table 3 shows that the calculated isotropic HFCs for all the tyrosyl radical split signal models agree very well with the associated experimental values. Moving on to consider the anisotropic HFCs, it can be seen that those calculated for the H3 and H5 protons are found in very good agreement with those determined from experiment. Table 3 shows disagreement between the calculated and experimental results for the $\mathrm{H} 2$ and H6 protons, where Nakazawa et al. found the same anisotropic HFCs for the $2 / 6$ protons as the $\mathrm{H} 7 \mathrm{~b}$ proton. Tommos et al. found similar experimental results, when studying the $\mathrm{Y}_{\mathrm{Z}}^{\bullet}$ radical of Synechocystis 6803 , to those shown in Table 3 apart from the anisotropic HFCs of the $\mathrm{H} 2$ and $\mathrm{H} 6$ protons which were found to be $\left(-3.5,0.2\right.$ and $2.7\left(T_{1}\right.$, $T_{2}$ and $\mathrm{T}_{3}$ respectively)). ${ }^{73}$ The experimental anisotropic HFCs reported by Tommos et al. are in better agreement with the calculated tyrosyl radical models. Of particular note in Table 3 is the good agreement observed for the $\mathrm{H} 7 \mathrm{a}$ and $\mathrm{H} 7 \mathrm{~b}$ protons of the tyrosyl methylene group. As has been substantially documented in the literature, these methylene protons receive spin density via hyperconjugation with the $\pi$-spin density of the ring system and their isotropic HFCs vary depending on the level of the overlap with the spin density. ${ }^{74}$ The extent of this overlap and therefore the resulting calculated hyperfine coupling is dependent on the $\mathrm{C} 8-\mathrm{C} 7-\mathrm{C} 1-\mathrm{C} 2$ dihedral angle. ${ }^{60}$ In the literature discussions on this topic the "dihedral angles" typically discussed are the angles between the H7 protons and a hypothetical $\mathrm{p}_{\mathrm{z}}$ orbital of $\mathrm{C} 1$ assuming ideal tetrahedral geometry. This is shown in Figure 8 where the calculated values of this study are compared with the experimentally determined values, from this it can be seen that the calculated values are 
found to be within the experimental error in determining these angles. It should be noted that similar results for the experimental angles have been found by Tommos et al. for the $\mathrm{Y}_{\mathrm{Z}}^{\bullet}$ found in Synechocystis $6803,{ }^{73}$ similar EPR studies performed on the $\mathrm{Y}_{\mathrm{D}}^{\bullet}$ residue of PSII have found there to be a difference in the reported HFCs and angles. ${ }^{75,76}$ This has been interpreted to indicate that the protein environments of the $\mathrm{Y}_{\mathrm{Z}}$ residue remain relatively similar between species but there is a larger difference in the environments of the $Y_{D}$ residue. ${ }^{46,61,72}$ The reasoning behind this has been linked to the roles of the $Y_{Z}$ and $Y_{D}$ residues in photosynthesis; the $\mathrm{Y}_{\mathrm{Z}}$ residue is responsible for electron transfer between the OEC and the $\mathrm{P}_{680}$ reaction centre and therefore central to water oxidation. ${ }^{77}$ Whereas the $Y_{D}$ residue is not required for correct PSII function and debate still rages as to its role in PSII, ${ }^{45,76,78}$ as a result of this the local protein environment of $Y_{D}$ may be more amenable to changes. It is hoped that these calculations, supported by further studies of the $\mathrm{Y}_{\mathrm{Z}} \bullet$ as well as the $\mathrm{Y}_{\mathrm{D}}^{\bullet}$ of PSII from a number of different species may provide more light to this important topic. 


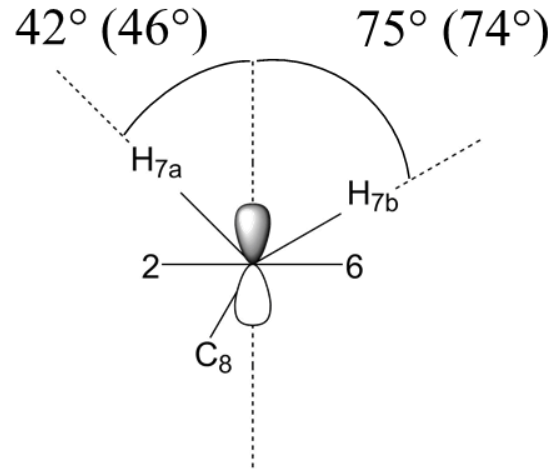

Ca-O

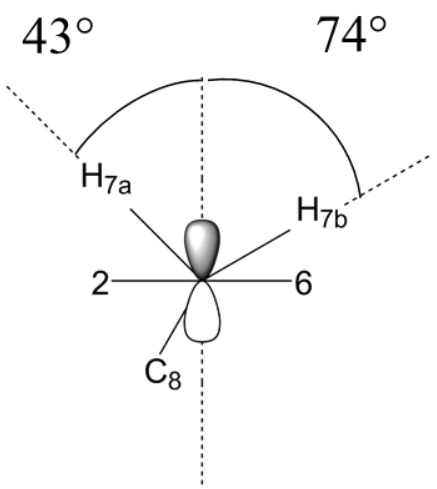

Sr-O

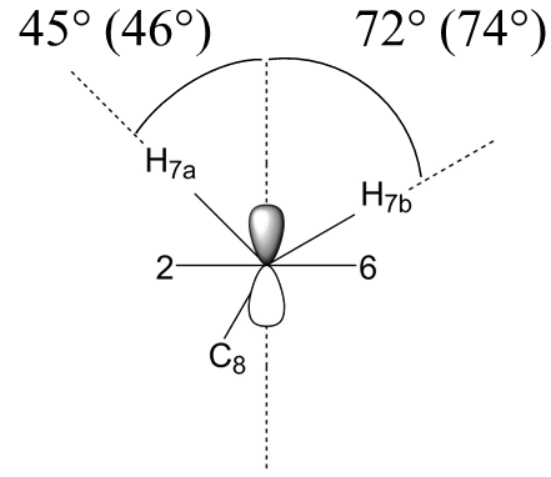

Ca-C

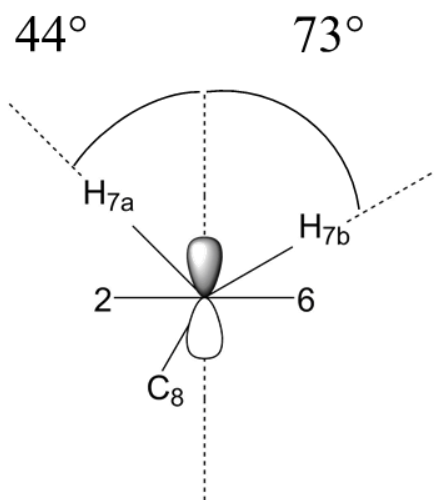

Sr-C

Figure 8. Comparison between calculated and experimentally derived orientations for the $\mathrm{Y}_{\mathrm{Z}}^{\bullet}$ methylene hydrogens, $\mathrm{H} 7 \mathrm{a}$ and $\mathrm{H} 7 \mathrm{~b}$ with respect to $\mathrm{C} 1 " \mathrm{p}_{z}$ ” orbital (see text for details). The experimentally derived values from Nakazawa et al are shown in brackets for the native OEC. ${ }^{72}$ Note that Tommos et al. have found similar experimental values of $44^{\circ}$ and $76^{\circ} .73$

The $S_{3}$ State.

\section{Geometry.}

It is currently believed that on progressing from the $S_{2}$ to the $S_{3}$ state an additional water derived ligand coordinates to the OEC resulting in a conformational change in the structure. ${ }^{79}$ This open coordination position along the Jahn-Teller axis of $\mathrm{Mn}^{\mathrm{III}}$ is present 
on either $\mathrm{Mn}_{\mathrm{A}}$ (closed cubane $\mathrm{S}_{2}$ ) or $\mathrm{Mn}_{\mathrm{D}}$ (open cubane $\mathrm{S}_{2}$ ). Deprotonation also occurs before progression to $S_{3}$. The combination of deprotonation and hexa coordination leads to oxidation of the remaining $\mathrm{Mn}^{\mathrm{III}}$ ion to $\mathrm{Mn}^{\mathrm{IV}}$ with reduction of $\mathrm{Y}_{\mathrm{Z}}^{\bullet}$ to $\mathrm{Y}_{\mathrm{Z}}$. In one scenario, this series of events was modelled by inserting an additional hydroxide ligand in the open coordination site of the $\mathrm{Mn}^{\mathrm{III}}$ ion of the $\mathrm{S}_{2} \mathrm{Y}_{\mathrm{Z}} \bullet$ state. (These models are indicated by the $\mathrm{W}_{\mathrm{x}}$ label). In addition, the water ligands (W1, W3 and W4) were selectively deprotonated in the $\mathrm{S}_{2} \mathrm{Y}_{\mathrm{Z}}^{\bullet}$ state to see if any ligand rearrangements occurred during subsequent geometry optimisation. The only instance where this did occur was in the closed form of the Ca model (Ca-C) where W3 in its hydroxide form ligates to $\mathrm{Mn}_{\mathrm{A}}$ which was oxidised to $\mathrm{Mn}^{\mathrm{IV}}$ with reduction of $\mathrm{Y}_{\mathrm{Z}}^{\bullet}$ (this model is described by the $\mathrm{W}_{3}$ label). A similar shift of deprotonated W3 on geometry optimisation has been reported by Ugur et al. who observed W3 hydroxide movement in both open and closed forms of the native OEC. ${ }^{80}$ The observation concerning W3 movement in the open form was not observed in this study. Of particular note also is that a similar W3 shift in ligation could not be observed in either the Sr-C or Sr-O models. Analysis of the Mulliken spin populations for the open and closed Ca and Sr models studied found that the additional coordination of the hydroxide ligand to the vacant $\mathrm{Mn}^{\mathrm{III}}$ coordination site resulted, on subsequent geometry optimisation, in an oxidation change from $\mathrm{Mn}^{\mathrm{III}}$ to $\mathrm{Mn}^{\mathrm{IV}}$ with reduction of $\mathrm{Y}_{\mathrm{Z}^{\bullet}}$. This resulted in all the manganese ions of the OEC being hexa coordinated and in the $\mathrm{Mn}^{\mathrm{IV}}$ state. Key interatomic distances for the models studied can be seen in Table 4. Considering firstly the Ca results, it can be seen that the $\mathbf{C a - O} \mathbf{W}_{\mathbf{X}}$ model provides $\mathrm{Mn}-\mathrm{Mn}$ distances which are in very good agreement with the experimental EXAFS data. ${ }^{81,82}$ Looking at the closed form Ca model with either $\mathbf{W}_{\mathbf{x}}$ or $\mathbf{W}_{\mathbf{3}}$, it can be seen from Table 4 that the calculated interatomic distances are broadly consistent with the EXAFS data. Table 4 also includes interatomic distances for the optimised $\mathbf{S r}$ models, although the changes to the $S_{3} \mathrm{Mn}-\mathrm{Mn}$ values following 
strontium substitution have not been experimentally determined. From Table 4 it can be seen that there are only small changes to the OEC core structure as a result of strontium substitution.

Table 4. Selected interatomic distances $(\AA)$ of the $S_{3}$ models and comparison with available native $S_{3}$ state experimental data.

\begin{tabular}{|c|c|c|c|c|c|c|}
\hline $\begin{array}{c}\text { Interatomic } \\
\text { Distance }\end{array}$ & $\mathrm{Ca}-\mathrm{O} \mathrm{W}_{\mathrm{x}}$ & $\mathrm{Sr}-\mathrm{O} \mathrm{W}_{\mathrm{X}}$ & Ca-C Wx & $\mathrm{Ca}-\mathrm{C} \mathrm{W}$ & $\mathrm{Sr}-\mathrm{C} \mathrm{W} \mathbf{x}$ & Exp. $^{\text {a) }}$ \\
\hline $\mathrm{Mn}_{\mathrm{A}}-\mathrm{Mn}_{\mathrm{B}}$ & 2.80 & 2.82 & 3.27 & 3.25 & 3.29 & \\
\hline $\mathrm{Mn}_{\mathrm{B}}-\mathrm{Mn}_{\mathrm{C}}$ & 2.82 & 2.85 & 2.80 & 2.81 & 2.82 & $2.80,3.3$ \\
\hline$M n_{C}-M_{D}$ & 2.81 & 2.83 & 2.75 & 2.76 & 2.78 & $(3: 1)$ \\
\hline $\mathrm{Mn}_{\mathrm{B}}-\mathrm{Mn}_{\mathrm{D}}$ & 3.51 & 3.52 & 2.91 & 2.92 & 2.93 & \\
\hline $\begin{array}{c}\mathrm{Mn}_{\mathrm{A}, \mathrm{B}, \mathrm{C}, \mathrm{D}}- \\
\mathrm{Ca} / \mathrm{Sr}\end{array}$ & $\begin{array}{c}3.99,3.39 \\
3.35,3.50\end{array}$ & $\begin{array}{c}4.02,3.45 \\
3.42,3.54\end{array}$ & $\begin{array}{c}3.99,3.32 \\
3.41,3.51\end{array}$ & $\begin{array}{l}3.98,3.34 \\
3.41,3.52\end{array}$ & $\begin{array}{l}4.04,3.37 \\
3.44,3.54\end{array}$ & $\begin{array}{c}3.4,4.0 \\
(2: 2 \text { or } \\
3: 1)\end{array}$ \\
\hline $\mathrm{Mn}_{\mathrm{A}}-\mathrm{W} 1$ & 2.00 & 2.04 & 2.05 & 2.06 & 2.05 & - \\
\hline $\mathrm{Mn}_{\mathrm{A}}-\mathrm{W} 2$ & 1.79 & 1.81 & 1.80 & 1.81 & 1.80 & - \\
\hline $\mathrm{Ca} / \mathrm{Sr}-\mathrm{W} 3$ & 2.35 & 2.56 & 2.35 & $2.50^{\mathrm{b})}$ & 2.57 & - \\
\hline $\mathrm{Ca} / \mathrm{Sr}-\mathrm{W} 4$ & 2.37 & 2.58 & 2.36 & 2.57 & 2.59 & - \\
\hline
\end{tabular}

Heisenberg Exchange Coupling Constants.

Figure 9 illustrates the calculated Heisenberg exchange coupling constants $\left(J_{i j}\right)$ for the $S_{3}$ models studied as well as the ground and first excited spin states and the energy difference between them. All $S_{3}$ models produce an effective total spin $S_{t}=3$ ground state and an $S_{t}=$ 4 first excited state in line with observations from experimental EPR and other computational studies. ${ }^{15}$

Examining the $\mathrm{J}$ coupling topology of the different $\mathrm{S}_{3}$ models, shows that the open and closed cubane forms display different magnetic connectivity. For the open form models, Ca-O $\mathbf{W}_{\mathbf{X}}$ and Sr-O $\mathbf{W}_{\mathbf{X}}$, three main exchange pathways are found: i) a ferromagnetic 
coupling between $\mathrm{Mn}_{\mathrm{C}}$ and $\mathrm{Mn}_{\mathrm{D}}\left(J_{\mathrm{CD}}\right)$; ii) a ferromagnetic coupling between the $\mathrm{Mn}_{\mathrm{B}}$ and $\operatorname{Mn}_{\mathrm{C}}\left(J_{\mathrm{BC}}\right)$; and iii) an antiferromagnetic coupling between $\mathrm{Mn}_{\mathrm{A}}$ and $\mathrm{Mn}_{\mathrm{B}}\left(J_{\mathrm{AB}}\right)$. The remaining exchange couplings $\left(J_{\mathrm{AC}}, J_{\mathrm{AD}}\right.$ and $\left.J_{\mathrm{BD}}\right)$ are considerably smaller reflecting the larger distances between the ions. The coupling topology can be described by a dimer of dimers model ${ }^{83}$ made up of two interacting dimer units, $\mathrm{S}_{\mathrm{A}}$ comprising $\mathrm{Mn}_{\mathrm{A}}$ and $\mathrm{Mn}_{\mathrm{B}}$ and $\mathrm{S}_{\mathrm{B}}\left(\mathrm{Mn}_{\mathrm{C}}\right.$ and $\left.M \mathrm{n}_{\mathrm{D}}\right)$. Antiferromagnetic coupling observed between $\mathrm{Mn}_{\mathrm{A}}$ and $\operatorname{Mn}_{\mathrm{B}}\left(J_{\mathrm{AB}}\right)$ results in a low spin dimer subunit of total spin $S_{X}=0$. Ferromagnetic coupling between $\mathrm{Mn}_{\mathrm{C}}$ and $\mathrm{Mn}_{\mathrm{D}}\left(J_{\mathrm{CD}}\right)$ leads to a high spin dimer of total spin $\mathrm{S}_{\mathrm{Y}}=3$. The interaction between these two dimer subunits then results in the overall $S_{t}=3$ observed. The closed form magnetic connectivity can best be explained using a monomer-trimer model. The trimer comprising $\mathrm{Mn}_{\mathrm{B}}-\mathrm{Mn}_{\mathrm{C}}-\mathrm{Mn}_{\mathrm{D}}$ coupled ferromagnetically producing a high spin fragment $\left(S_{X}=9 / 2\right)$. This spin state is a characteristic feature of biomimetic models which feature a $\mathrm{Mn}_{3}{ }_{3} \mathrm{O}_{4} \mathrm{Ca}$ unit with the internal geometry of the cubane dictating the ferromagnetic character of the coupling within the cubane. ${ }^{86,87}$ The antiferromagnetic coupling between this trimer in the OEC and the $\mathrm{S}=3 / 2 \mathrm{Mn}_{\mathrm{A}}$, described by the $J_{\mathrm{AB}}$ coupling then produces the ground state spin of $S=3$. The effects of strontium substitution on the $S_{3}$ state, Figure 9, shows there to be only minor changes to the calculated exchange coupling values indicating that the substitution has little or no effect on the underlying magnetic structure of the models studied. 

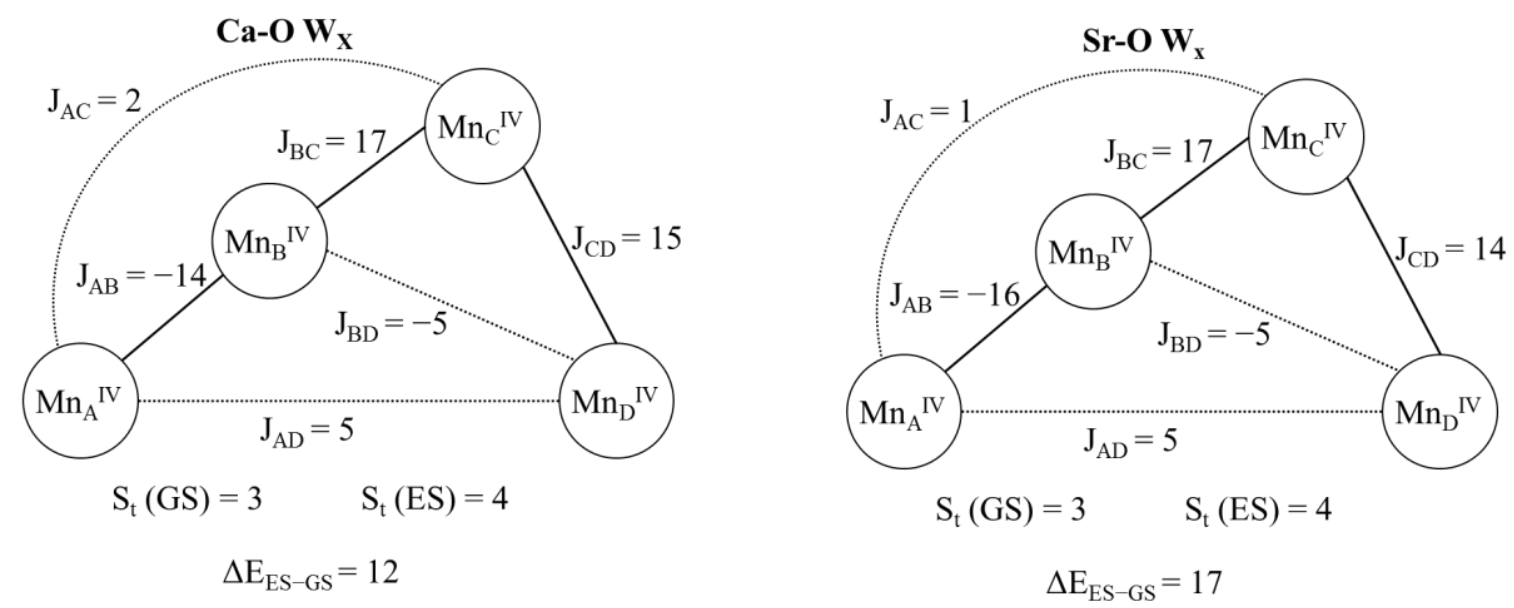

$$
\begin{gathered}
\mathrm{S}_{\mathrm{t}}(\mathrm{GS})=3 \quad \mathrm{~S}_{\mathrm{t}}(\mathrm{ES})=4 \\
\Delta \mathrm{E}_{\mathrm{ES}-\mathrm{GS}}=17
\end{gathered}
$$
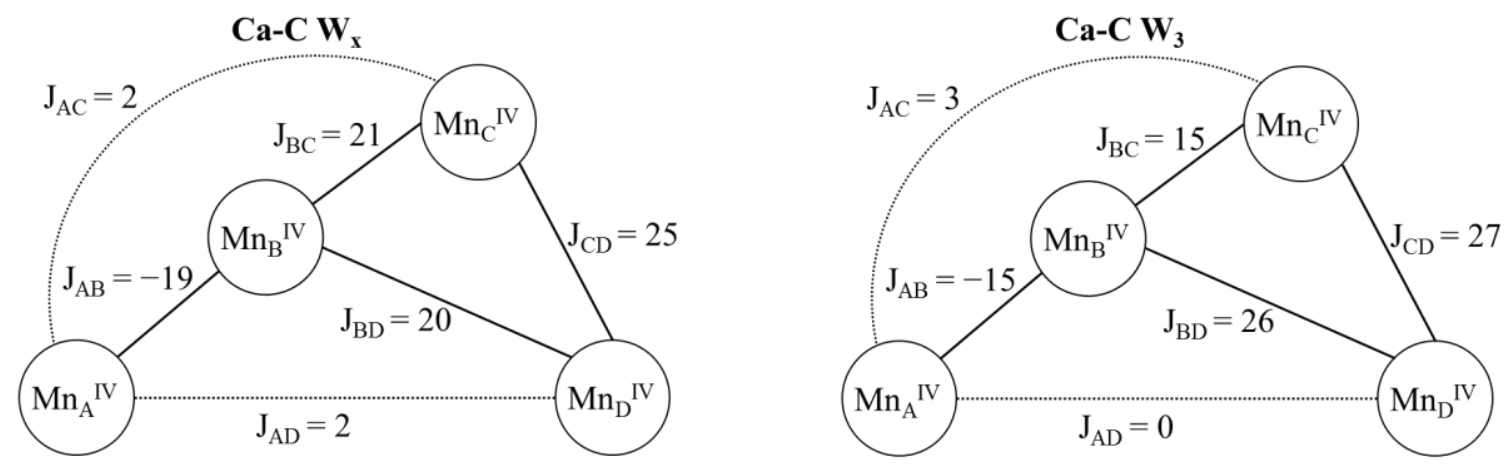

$$
\begin{gathered}
\mathrm{S}_{\mathrm{t}}(\mathrm{GS})=3 \quad \mathrm{~S}_{\mathrm{t}}(\mathrm{ES})=4 \\
\Delta \mathrm{E}_{\mathrm{ES}-\mathrm{GS}}=33
\end{gathered}
$$

$$
\mathrm{S}_{\mathrm{t}}(\mathrm{GS})=3 \quad \mathrm{~S}_{\mathrm{t}}(\mathrm{ES})=4
$$$$
\Delta \mathrm{E}_{\mathrm{ES}-\mathrm{GS}}=29
$$

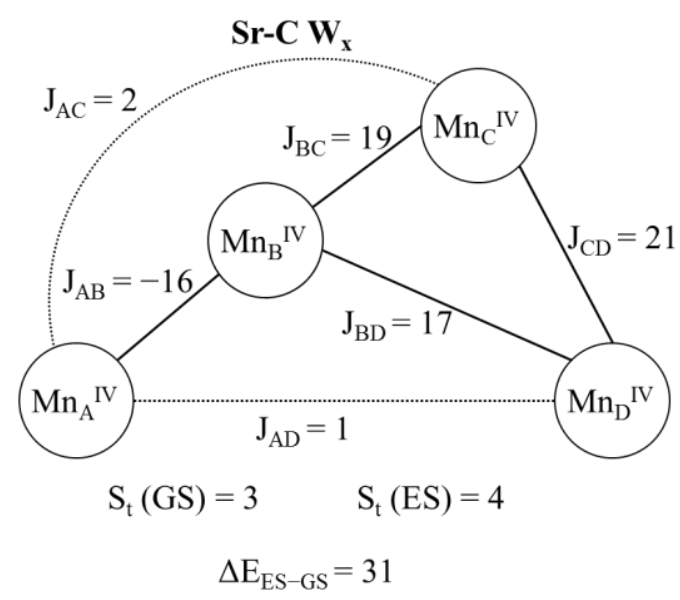

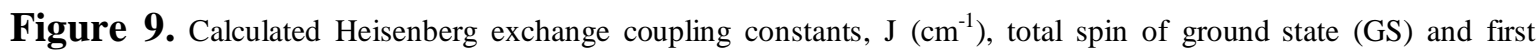
excited state (ES) as well as the energetic separation between the two lowest energy levels $\left(\mathrm{cm}^{-1}\right)$ for the investigated $\mathrm{S}_{3}$ models. 


\section{Spin Projection Coefficients.}

All of the $S_{3}$ state cluster models produce a coupling topology of ' $\beta \alpha \alpha \alpha$ ' with a negative spin projection coefficient being found for $\mathrm{Mn}_{\mathrm{A}}$ and positive spin projection coefficients being found for all other manganese ions of the OEC. Table 5 shows that the manganese ions of the Ca-O $\mathbf{W}_{\mathbf{X}}$ model couple in such a manner so that the on-site spin projection coefficients can be categorised into two unique classes: $M n_{C}$ and $M n_{D}$ are found to possess a spin projection coefficient of roughly 0.5 , with the $\mathrm{Mn}_{\mathrm{A}}$ and $\mathrm{Mn}_{\mathrm{B}}$ possessing significantly smaller on-site spin projection coefficients in the range of 0.1 to 0.2 approximately. For Ca-C models (in either the $\mathrm{W}_{\mathrm{x}}$ attack or $\mathrm{W}_{3}$ attack scenario) the on-site spin projection coefficients are of a similar magnitude. The $\mathbf{S r}$ models show identical patterns to their $\mathrm{Ca}$ analogues.

Table 5. Calculated on-site spin projection coefficients, $c_{i}$, for the investigated OEC $S_{3}$ models.

\begin{tabular}{lccccc}
\hline & $\mathrm{Mn}_{\mathrm{A}}$ & $\mathrm{Mn}_{\mathrm{B}}$ & $\mathrm{Mn}_{\mathrm{C}}$ & $\mathrm{Mn}_{\mathrm{D}}$ & Coupling \\
\hline Ca-O W & -0.121 & 0.171 & 0.459 & 0.490 & $\beta \alpha \alpha \alpha$ \\
Sr-O W $\mathbf{X}$ & -0.106 & 0.164 & 0.456 & 0.487 & $\beta \alpha \alpha \alpha$ \\
Ca-C W & -0.362 & 0.416 & 0.473 & 0.473 & $\beta \alpha \alpha \alpha$ \\
Ca-C W & -0.366 & 0.424 & 0.474 & 0.467 & $\beta \alpha \alpha \alpha$ \\
Sr-C W & -0.362 & 0.415 & 0.474 & 0.473 & $\beta \alpha \alpha \alpha$ \\
\hline
\end{tabular}

\section{${ }^{55} \mathrm{Mn}$ Hyperfine Couplings.}

Table 6 shows the isotropic and anisotropic hyperfine couplings (HFCs) calculated for all the $S_{3}$ state models using the on-site spin projection coefficients shown in Table 5 . In addition to this, Table 6 also shows experimental W-band ${ }^{55} \mathrm{Mn}$-EDNMR data by Cox et al. on the native OEC in the $\mathrm{S}_{3}$ state. ${ }^{15}$ Cox et al. found the HFCs for the four manganese ions could be separated into two classes. The strongly coupled HFC class 
which was found to have an $A_{\text {iso }}$ around $100 \mathrm{MHz}$ and the more weakly coupled class having an isotropic couplings of a few MHz. ${ }^{15}$ In addition to the two HFC classes, Cox et al. also reported small hyperfine anisotropy for all the manganese ions which was interpreted as evidence of the presence of $\mathrm{Mn}^{\mathrm{IV}}$ ions with octahedral coordination geometry in the $\mathrm{S}_{3}$ state of the OEC. Experimental and computational studies of biomimetic complexes which contain $\mathrm{Mn}^{\mathrm{IV}}$ ions with trigonal bipyramidal geometry as well as all $\mathrm{Mn}^{\mathrm{III}}$ complexes have found larger hyperfine anisotropies. ${ }^{85-88}$ All of the $S_{3}$ models studied in this section find the four manganese ions to have the same oxidation state $\left(\mathrm{Mn}^{\mathrm{IV}}\right)$ and also possess similar octahedral coordination environments. The similar environments should lead to similar on-site HFC values for all $\mathrm{Mn}$ ions and the differences in the experimentally measured coupled values lie in different spin projection coefficients for the four Mn ions. From Table 6 it can be seen that the calculated isotropic HFCs for the Ca-O $\mathbf{W}_{\mathbf{X}}$ model are in reasonable agreement with the experimental values. In particular the two large HFCs calculated at $-87 \mathrm{MHz}$ and $-88 \mathrm{MHz}$ are in good agreement with the larger set of experimental HFCs in terms of magnitude and sign. The calculated smaller set of couplings for $\mathrm{Mn}_{\mathrm{C}}$ and $\mathrm{Mn}_{\mathrm{D}}$ are significantly larger than the experimental values however. Similar findings have been found by Cox et al ${ }^{15}$ and Krewald et al ${ }^{89}$. It should be noted that the two smaller experimental HFCs, by virtue of their smaller magnitude, could not be completely characterised in the experimental study. ${ }^{15}$ In particular the anisotropy was not specifically determined but assumed to be small. The calculated HFCs for the closed form of the native OEC in either the $\mathbf{C a}-\mathbf{C} \mathbf{W}_{\mathbf{X}}$ or $\mathbf{C a}-\mathbf{C} \mathbf{W}_{\mathbf{3}}$ models, Table 6 , are in poorer agreement with the experimental data as the magnitudes of the calculated isotropic HFC in both models are broadly similar across all four manganese ions and do not separate into two distinctive levels of calculated isotropic HFC. This can be rationalised by the broadly similar spin projection coefficients reported in Table 5 for the closed forms. Our BS-DFT 
analysis therefore broadly supports an open cubane form of the $S_{3}$ state with hydroxo - oxo hydrogen bonding between the nearby oxygens which then presumably undergo O-O bond formation in the $\mathrm{S}_{4}$ state.

Table 6 also shows calculated HFC data for the Sr substituted form where identical trends to the native $\mathrm{Ca}$ form are observed between the open and closed forms of the OEC. As already noted above geometry optimisation on W3 deprotonation leads to a minimum energy structure with the W3 $(\mathrm{OH})$ ligated to Sr. This contrasts with the Ca form where this movement was observed to spontaneously occur on W3 deprotonation leading to a minimum energy structure with the $\mathrm{W} 3(\mathrm{OH})$ ligated to $\mathrm{Mn}_{\mathrm{D}}(\mathrm{IV})$. Currently we do not have an obvious reason for this different behaviour between $\mathrm{Ca}$ and $\mathrm{Sr}$ models, and possible sources are being investigated. Absence of movement of W3 hydroxide for the $\mathrm{Sr}$ form results in $\mathrm{Mn}_{\mathrm{D}}$ remaining unoxidised as $\mathrm{Mn}^{\mathrm{III}}$ in the $\mathrm{S}_{3}$ state. It would be expected therefore that the EPR properties of the $S_{3}$ state for the Sr substituted samples would be quite different to the native $\mathrm{Ca}$ form as the presence a $\mathrm{Mn}^{\mathrm{III}}$ ion would introduce higher anisotropy. Clearly inhibited movement of the second substrate water on $\mathrm{Sr}$ substitution would provide an explanation for the lower activity observed for this form of the catalyst.

Table 6. Calculated ${ }^{55} \mathrm{Mn}$ hyperfine couplings (in $\mathrm{MHz}$ ) for the $\mathrm{S}_{3}$ models and comparison with experimental data.

\begin{tabular}{cccccc}
\hline Model & & $A_{\text {iso }}$ & $T_{1}$ & $T_{2}$ & $T_{3}$ \\
\hline \multirow{5}{*}{ Ca-O W } & $\mathrm{Mn}_{\mathrm{A}}$ & 28 & -2 & 1 & 1 \\
& $\mathrm{Mn}_{\mathrm{B}}$ & -42 & -4 & 1 & 3 \\
& $\mathrm{Mn}_{\mathrm{C}}$ & -87 & -3 & 1 & 2 \\
& $\mathrm{Mn}_{\mathrm{D}}$ & -88 & -4 & 1 & 3 \\
\hline \multirow{5}{*}{ Sr-O W $\mathbf{W}_{\mathbf{X}}$} & $\mathrm{Mn}_{\mathrm{A}}$ & 25 & -1 & 0 & 1 \\
& $\mathrm{Mn}_{\mathrm{B}}$ & -40 & -3 & 1 & 2 \\
& $\mathrm{Mn}_{\mathrm{C}}$ & -87 & -4 & 1 & 3 \\
& $\mathrm{Mn}_{\mathrm{D}}$ & -88 & -4 & 2 & 3 \\
\hline
\end{tabular}




\begin{tabular}{cccccc}
\hline \multirow{5}{*}{ Ca-C $\mathbf{W}_{\mathbf{X}}$} & $\mathrm{Mn}_{\mathrm{A}}$ & 72 & -4 & 1 & 3 \\
& $\mathrm{Mn}_{\mathrm{B}}$ & -67 & -4 & 2 & 2 \\
& $\mathrm{Mn}_{\mathrm{C}}$ & -84 & -1 & 0 & 1 \\
& $\mathrm{Mn}_{\mathrm{D}}$ & -80 & -2 & 1 & 1 \\
\hline \multirow{5}{*}{ Ca-C $\mathbf{W}_{\mathbf{3}}$} & $\mathrm{Mn}_{\mathrm{A}}$ & 75 & -4 & 2 & 2 \\
& $\mathrm{Mn}_{\mathrm{B}}$ & -59 & -4 & 1 & 3 \\
& $\mathrm{Mn}_{\mathrm{C}}$ & -86 & -3 & 1 & 2 \\
& $\mathrm{Mn}_{\mathrm{D}}$ & -81 & -2 & 1 & 1 \\
\hline \multirow{5}{*}{ Sr-C $\mathbf{W}_{\mathbf{X}}$} & $\mathrm{Mn}_{\mathrm{A}}$ & 74 & -4 & 1 & 3 \\
& $\mathrm{Mn}_{\mathrm{B}}$ & -64 & -3 & 1 & 2 \\
& $\mathrm{Mn}_{\mathrm{C}}$ & -81 & -3 & 1 & 2 \\
& $\mathrm{Mn}_{\mathrm{D}}$ & -77 & -4 & 2 & 2 \\
\hline \multirow{3}{*}{ Exp. $^{15}$} & 1 & -99.0 & -1.2 & -1.2 & 2.4 \\
& 2 & -95.6 & -3.8 & 1.8 & 1.8 \\
& $3^{\text {a),b) }}$ & -25.9 or +7.0 & - & - & - \\
& $4^{\text {b) }}$ & $0.5(\leq 5)$ & - & - & - \\
\hline
\end{tabular}

$\mathrm{T}_{\mathrm{i}}$ represents the traceless parts of the anisotropic tensor. ${ }^{\text {a) }}$ The experimental value of $\mathrm{A}_{3}$ is dependent upon the assumed sign of the hyperfine coupling, It could potentially take either one of the two values shown in Table .6. ${ }^{\text {b) }}$ The $\mathrm{A}_{3}$ and $\mathrm{A}_{4}$ hyperfine couplings are experimentally assumed to be isotropic.

\section{$S_{3}$-peroxo model}

As mentioned in the introduction atomic level structures for the $S_{3}$ state have very recently been reported using XFEL crystallography. ${ }^{17,16}$ In one case, Suga et al ${ }^{16}$, an extra oxygen atom has been located compared with the $\mathrm{S}_{1}$ state which is similar to the additional $\mathrm{OH}$ ligand of our open form models. The crystal structure $\mathrm{O}-\mathrm{O}$ bond distance of $1.5 \AA$ is however much shorter than the average $2.4 \AA$ value found in our oxo-hydroxo $\mathrm{S}_{3}$ models. The short O-O bond distance reported in the XFEL structure of Suga et al ${ }^{16}$ indicates peroxo ligand formation has occurred rather than an oxo-hydroxo interaction that we locate in our models and similar ones reported by Cox et al. ${ }^{15}$ and Krewald et al. ${ }^{89}$ To test the feasibility of peroxo formation in $S_{3}$, an OEC model, using as starting structure the XFEL coordinates has been geometry optimised assuming peroxo formation. The minimum energy structure, Figure 10, shows minimal differences to the XFEL determination and agrees with $\mathrm{S}_{3}$ EXAFS structural data, thereby indicating that this is, structurally, a highly viable model for the $S_{3}$ state. Based on Mulliken population analysis, 
both $\mathrm{Mn}_{\mathrm{A}}$ and $\mathrm{Mn}_{\mathrm{D}}$ are in oxidation state III with $\mathrm{Mn}_{\mathrm{B}}$ and $\mathrm{Mn}_{\mathrm{C}}$ present in oxidation state IV. The Jahn-Teller axis for both $\mathrm{Mn}_{\mathrm{A}}$ and $\mathrm{Mn}_{\mathrm{D}}$ lies along their respective bonds to the peroxo oxygen atoms, see Figure 10. Similar to the XFEL starting coordinates, distinctive ligation of the peroxo oxygen atoms is found, where one of the peroxo oxygens is ligated to $\mathrm{Mn}_{\mathrm{B}}(1.9 \AA), \mathrm{Mn}_{\mathrm{A}}(2.2 \AA)$ and $\mathrm{Ca}(2.4 \AA)$ with the other peroxo oxygen ligated solely to $\mathrm{Mn}_{\mathrm{D}}(2.1 \AA)$. A DFT exchange coupling analysis gives rise to an $\mathrm{S}=3$ ground state in agreement with $\mathrm{S}_{3}$ EPR determinations, Sanakis et al ${ }^{90}$, Boussac et al ${ }^{91}$. Intriguingly as well, the $S=3$ ground state can be rationalised within a dimer of dimers model with an $S_{X}$ $=0$ dimer fragment (antiferromagnetic coupling, accommodated by superexchange via the peroxo ligand, between $\mathrm{Mn}(\mathrm{III})_{\mathrm{A}}$ and $\mathrm{Mn}(\mathrm{III})_{\mathrm{D}}$ ) coupled with an $\mathrm{S}_{\mathrm{Y}}=3$ (ferromagnetic coupling between $\mathrm{Mn}(\mathrm{IV})_{\mathrm{B}}$ and $\mathrm{Mn}(\mathrm{IV})_{\mathrm{C}}$. The low spin $\mathrm{S}_{\mathrm{X}}=0$ dimer would render it EPR silent. This coupling scheme would give rise to $\mathrm{Mn}_{\mathrm{A}}$ and $\mathrm{Mn}_{\mathrm{D}}$ spin projections close to zero and $\mathrm{Mn}_{\mathrm{B}}$ and $\mathrm{Mn}_{\mathrm{C}}$ spin projections close to 0.5 , leading to two large ${ }^{55} \mathrm{Mn}$ isotropic hfcs from $\mathrm{Mn}_{\mathrm{B}}$ and $\mathrm{Mn}_{\mathrm{C}}$ and close to zero small magnitude values for $\mathrm{Mn}_{\mathrm{D}}$ and $\mathrm{Mn}_{\mathrm{A}}$. This is similar to the pattern of ${ }^{55} \mathrm{Mn}$ hfcs obtained experimentally by Cox et al. ${ }^{15}$ Because the $\mathrm{Mn}(\mathrm{III})_{\mathrm{A}} / \mathrm{Mn}(\mathrm{III})_{\mathrm{D}}$ dimer is EPR silent, an overall low anisotropy would be expected. It is therefore possible to explain the $S_{3} E P R$ characteristics based on the peroxo model revealed in the XFEL study of Suga et $\mathrm{al}^{16}$. Another possibility is that an equilibrium exists between the peroxo and oxo-hydroxo species as proposed some years ago by Renger ${ }^{92}$ and references therein and more recently by Isobe et al ${ }^{93} \cdot{ }^{18} \mathrm{O} /{ }^{16} \mathrm{O}$ isotope water exchange rates $^{94}$ which show two different rates for substrate waters in the $S_{3}$ state, have been argued to rule out peroxo formation in this state. The distinctly different binding modes of the peroxo oxygens described above, Figure 10, could explain this however. The surprising similarity in exchange rates between $S_{2}$ and $S_{3}$ together with drastic reduction for the $S_{3} Y_{Z}$ - state are also difficult to incorporate in any current mechanism. X-ray absorption near 
edge structure (XANES) studies ${ }^{81}$ do not support Mn reduction in the $\mathrm{S}_{2}$ to $\mathrm{S}_{3}$ transition but here again the significant structural change to peroxo bridging ligation may complicate the edge shape and shift ${ }^{82}$. Clearly further clarification of the conflicting $\mathrm{S}_{3}$ structures and associated modelling studies needs to be performed to provide us with a definitive picture of the $S_{3}$ state, an essential step in determining any overall mechanism for water oxidation by the OEC. 


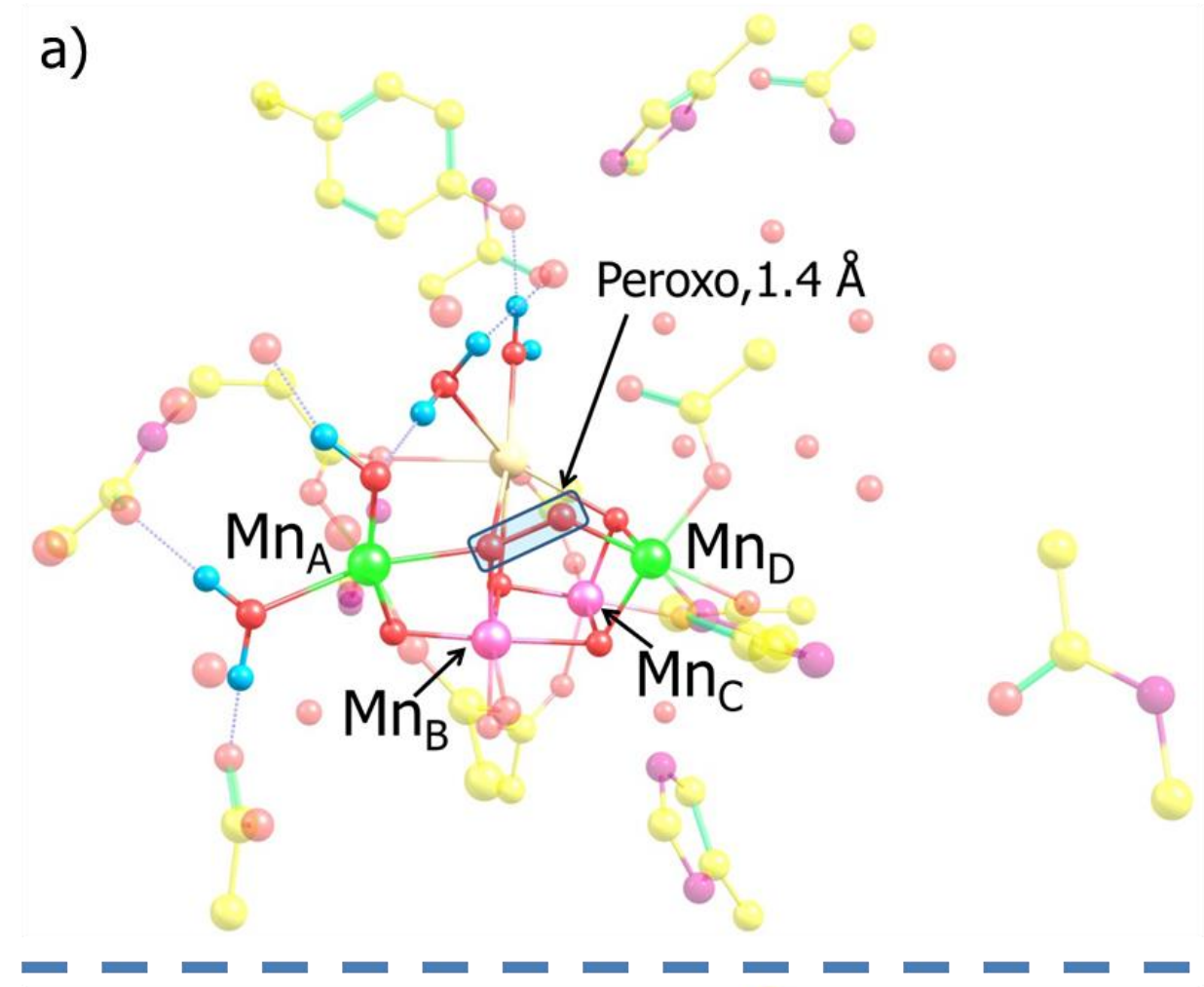

b)

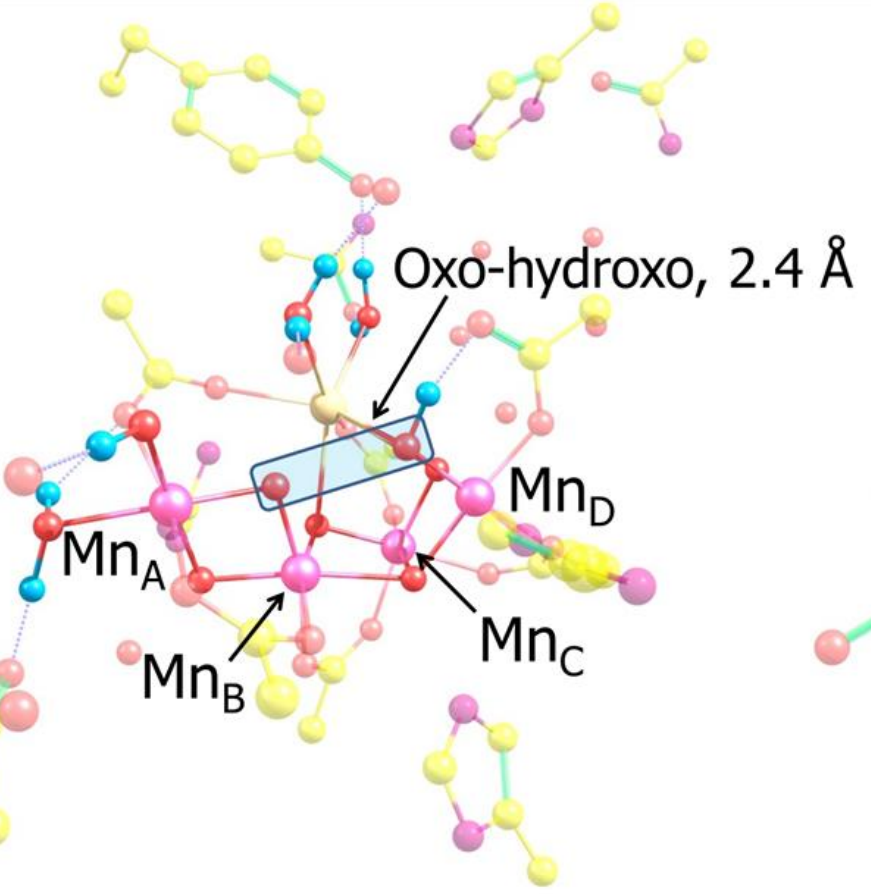

Figure 10. (a) Geometry optimised $S_{3}$-peroxo model. $\mathrm{Mn}_{\mathrm{A}}$ and $\mathrm{Mn}_{\mathrm{D}}$ are oxidation state III (green) and $\mathrm{Mn}_{\mathrm{C}}$ and $\mathrm{Mn}_{\mathrm{B}}$ are in oxidation state IV (purple). The peroxo bond of length $1.4 \AA$ is highlighted. (b) Geometry optimised $\mathrm{S}_{3}$ (oxohydroxo) model in its high spin state $\mathrm{Mn}_{\mathrm{A}}, \mathrm{Mn}_{\mathrm{D}} \mathrm{Mn}_{\mathrm{C}}$ and $\mathrm{Mn}_{\mathrm{B}}$ are in oxidation state IV (purple). The O-O bond distance of $2.4 \AA$ is highlighted. See text for details. 


\section{Conclusions}

In this study a BS-DFT magnetic analysis of the $\mathrm{S}_{2}, \mathrm{~S}_{2} \mathrm{Y}_{\mathrm{Z}}^{\bullet}$ and $\mathrm{S}_{3}$ states of Nature's oxygen evolving complex was performed for both the native $\mathrm{Ca}$ and $\mathrm{Sr}$ substituted forms. Excellent agreement with experimental data is observed between the tyrosyl calculated gtensor and ${ }^{1} \mathrm{H}$ hyperfine couplings for the native $\mathrm{Ca}$ form. Changes in the hydrogen bonding environment of the tyrosyl radical in $\mathrm{S}_{2} \mathrm{Y}_{\mathrm{Z}} \bullet$ caused by $\mathrm{Sr}$ substitution leads to notable changes in the calculated g-tensor of the tyrosyl radical. Comparison of calculated and experimental ${ }^{55} \mathrm{Mn}$ hyperfine couplings for the $\mathrm{S}_{3}$ state favours an open cubane form of the complex with an additional $\mathrm{OH}$ ligand coordinating to $\mathrm{Mn}_{\mathrm{D}}$. In $\mathrm{Ca}$ models this additional ligation can arise by closed-cubane form deprotonation of the Ca ligand W3 in the $\mathrm{S}_{2} \mathrm{Y}_{\mathrm{Z}}^{\bullet}$ state accompanied by movement to the vacant $\mathrm{Mn}$ coordination site or by addition of an external $\mathrm{OH}$ group. For the $\mathrm{Sr}$ form, no spontaneous movement of $\mathrm{W} 3$ to the vacant $\mathrm{Mn}$ coordination site is observed in contrast to the native $\mathrm{Ca}$ form. This difference may lead to the reduced catalytic activity of the Sr substituted form. The oxo -hydroxo bond distance for such $S_{3}$ models is much larger than that found in the XFEL study of the $\mathrm{S}_{3}$ state by Suga et al ${ }^{16}$ where the $\mathrm{O}-\mathrm{O}$ bond distance of $1.5 \AA$ indicates peroxo ligation. BS-DFT studies on such a peroxo model is shown to be consistent with the experimental structural data. In addition an $\mathrm{S}=3$ ground state is calculated in agreement with EPR studies indicating that this scenario needs further investigation.

\section{ACKNOWLEDGEMENTS}

NJB and TAC acknowledge support from the UK BBSRC Doctoral Training Partnership (DTP) program.

\section{ASSOCIATED CONTENT}




\section{Supporting Information}

Additional analysis of models, derivation of empirical scaling factor for ${ }^{55} \mathrm{Mn}$ isotropic hyperfine couplings plus representative model coordinates. Available free of charge at http://pubs.acs.org

\section{References}

(1) Blankenship, R. Molecular Mechanisms of Photosynthesis, 1st ed.; Blankenship, R. E., Ed.; Blackwell Science Ltd: Oxford, UK, 2002.

(2) Klauss, A.; Haumann, M.; Dau, H. Alternating Electron and Proton Transfer Steps in Photosynthetic Water Oxidation. Proc. Natl. Acad. Sci. 2012, 109 (40), 1603516040.

(3) Vinyard, D. J.; Brudvig, G. W. Progress Toward a Molecular Mechanism of Water Oxidation in Photosystem II. Annu. Rev. Phys. Chem. 2017, 68 (1), 101-116.

(4) Zahariou, G.; Chrysina, M.; Petrouleas, V.; Ioannidis, N. Can We Trap the Metalloradical Intermediate during the S-State Transitions of Photosystem II? An EPR Investigation. FEBS Lett. 2014, 588 (9), 1827-1831.

(5) Sjöholm, J.; Styring, S.; Havelius, K. G. V; Ho, F. M. Visible Light Induction of an Electron Paramagnetic Resonance Split Signal in Photosystem II in the S 2 State Reveals the Importance of Charges in the Oxygen-Evolving Center during Catalysis: A Unifying Model. Biochemistry 2012, 51 (10), 2054-2064.

(6) Su, J. H.; Havelius, K. G. V.; Mamedov, F.; Ho, F. M.; Styring, S. Split EPR Signals from Photosystem II Are Modified by Methanol, Reflecting S StateDependent Binding and Alterations in the Magnetic Coupling in the CaMn4 Cluster. Biochemistry 2006, 45 (24), 7617-7627.

(7) Cox, N.; Ho, F. M.; Pewnim, N.; Steffen, R.; Smith, P. J.; Havelius, K. G. V; Hughes, J. L.; Debono, L.; Styring, S.; Krausz, E.; et al. The $\mathrm{S}_{1}$ Split Signal of Photosystem II; A Tyrosine-Manganese Coupled Interaction. Biochim. Biophys. Acta - Bioenerg. 2009, 1787 (7), 882-889.

(8) Havelius, K. G. V.; Su, J. H.; Han, G.; Mamedov, F.; Ho, F. M.; Styring, S. The Formation of the Split EPR Signal from the $\mathrm{S}_{3}$ State of Photosystem II Does Not Involve Primary Charge Separation. Biochim. Biophys. Acta - Bioenerg. 2011, 1807 (1), 11-21.

(9) Havelius, K. G. V; Sjöholm, J.; Ho, F. M.; Mamedov, F.; Styring, S. Metalloradical EPR Signals from the $\mathrm{Y}_{\mathrm{Z}} \mathrm{S}$-State Intermediates in Photosystem II. Appl. Magn. Reson. 2010, 37 (1), 151-176. 
(10) Chrysina, M.; Zahariou, G.; Ioannidis, N.; Petrouleas, V. Conversion of the $\mathrm{g}=4.1$ EPR Signal to the Multiline Conformation during the $S_{2}$ to $S_{3}$ Transition of the Oxygen Evolving Complex of Photosystem II. Biochim. Biophys. Acta - Bioenerg. 2010, 1797 (4), 487-493.

(11) Haddy, A. EPR Spectroscopy of the Manganese Cluster of Photosystem II. Photosynth. Res. 2007, 92 (3), 357-368.

(12) Chrysina, M.; Zahariou, G.; Sanakis, Y.; Ioannidis, N.; Petrouleas, V. Conformational Changes of the S2YZ Intermediate of the $S_{2}$ to $S_{3}$ Transition in Photosystem II. J. Photochem. Photobiol. B Biol. 2011, 104 (1-2), 72-79.

(13) Dau, H.; Haumann, M. Eight Steps Preceding O-O Bond Formation in Oxygenic Photosynthesis--a Basic Reaction Cycle of the Photosystem II Manganese Complex. Biochim. Biophys. Acta 2007, 1767 (6), 472-483.

(14) Noguchi, T. FTIR Detection of Water Reactions in the Oxygen-Evolving Centre of Photosystem II. Philos. Trans. R. Soc. B Biol. Sci. 2008, 363 (1494), 1189-1195.

(15) Cox, N.; Retegan, M.; Neese, F.; Pantazis, D. A.; Boussac, A.; Lubitz, W. Photosynthesis. Electronic Structure of the Oxygen-Evolving Complex in Photosystem II prior to O-O Bond Formation. Science 2014, 345 (6198), 804-808.

(16) Suga, M.; Akita, F.; Sugahara, M.; Kubo, M.; Nakajima, Y.; Nakane, T.; Yamashita, K.; Umena, Y.; Nakabayashi, M.; Yamane, T.; et al. Light-Induced Structural Changes and the Site of $\mathrm{O}=\mathrm{O}$ Bond Formation in PSII Caught by XFEL. Nature 2017, 543 (7643), 131-135.

(17) Young, I. D.; Ibrahim, M.; Chatterjee, R.; Gul, S.; Fuller, F. D.; Koroidov, S.; Brewster, A. S.; Tran, R.; Alonso-Mori, R.; Kroll, T.; et al. Structure of Photosystem II and Substrate Binding at Room Temperature. Nature 2016, 540 (7633), 453-457.

(18) Wang, J.; Askerka, M.; Brudvig, G. W.; Batista, V. S. Crystallographic Data Support the Carousel Mechanism of Water Supply to the Oxygen-Evolving Complex of Photosystem II. ACS Energy Lett. 2017, 2 (10), 2299-2306.

(19) Kim, C. J.; Debus, R. J. Evidence from FTIR Difference Spectroscopy That a Substrate $\mathrm{H}_{2}$ Molecule for $\mathrm{O}_{2}$ Formation in Photosystem II Is Provided by the $\mathrm{Ca}$ Ion of the Catalytic $\mathrm{Mn}_{4} \mathrm{CaO}_{5}$ Cluster. Biochemistry 2017, 56 (20), 2558-2570.

(20) Askerka, M.; Brudvig, G. W.; Batista, V. S. The $\mathrm{O}_{2}$-Evolving Complex of Photosystem II: Recent Insights from Quantum Mechanics/Molecular Mechanics (QM/MM), Extended X-Ray Absorption Fine Structure (EXAFS), and Femtosecond X-Ray Crystallography Data. Acc. Chem. Res. 2017, 50 (1), 41-48.

(21) Pérez-Navarro, M.; Neese, F.; Lubitz, W.; Pantazis, D. A.; Cox, N. Recent Developments in Biological Water Oxidation. Curr. Opin. Chem. Biol. 2016, 31 (i), 113-119.

(22) Beal, N. J.; O’Malley, P. J. Manganese Oxidation State Assignment for Manganese Catalase. J. Am. Chem. Soc. 2016, 138 (13), 4358-4361.

Becke, A. D. Density-Functional Exchange-Energy Approximation with Correct 
Asymptotic Behavior. Phys. Rev. A 1988, 38 (6), 3098-3100.

(24) Perdew, J. Density-Functional Approximation for the Correlation Energy of the Inhomogeneous Electron Gas. Phys. Rev. B 1986, 33 (12), 8822-8824.

(25) Lenthe, E. Van; Baerends, E. J.; Snijders, J. G. Relativistic Regular TwoComponent Hamiltonians. J. Chem. Phys. 1993, 99 (6), 4597.

(26) van Lenthe, E.; Baerends, E. J.; Snijders, J. G. Relativistic Total Energy Using Regular Approximations. J. Chem. Phys. 1994, 101 (11), 9783.

(27) van Wüllen, C. Molecular Density Functional Calculations in the Regular Relativistic Approximation: Method, Application to Coinage Metal Diatomics, Hydrides, Fluorides and Chlorides, and Comparison with First-Order Relativistic Calculations. J. Chem. Phys. 1998, 109 (2), 392.

(28) Pantazis, D. A.; Chen, X. Y.; Landis, C. R.; Neese, F. All-Electron Scalar Relativistic Basis Sets for Third-Row Transition Metal Atoms. J. Chem. Theory Comput. 2008, 4 (6), 908-919.

(29) Weigend, F.; Ahlrichs, R. Balanced Basis Sets of Split Valence, Triple Zeta Valence and Quadruple Zeta Valence Quality for $\mathrm{H}$ to Rn: Design and Assessment of Accuracy. Phys. Chem. Chem. Phys. 2005, 7 (18), 3297.

(30) Eichkorn, K.; Htiser, M.; Ahlrichs, R.; Eichkorn, K.; Treutler, O.; Marco, H.; Ahlrichs, R. Auxiliary Basis Sets to Approximate Coulomb Potentials Chem . Phys . Letters 240 ( 1995 ) 283

(31) Eichkorn, K.; Weigend, F.; Treutler, O.; Ahlrichs, R. Auxiliary Basis Sets for Main Row Atoms and Transition Metals and Their Use to Approximate Coulomb Potentials. Theor. Chem. Acc. 1997, 97 (1-4), 119-124.

(32) Weigend, F. Accurate Coulomb-Fitting Basis Sets for H to Rn. Phys. Chem. Chem. Phys. 2006, 8 (9), 1057-1065.

(33) Grimme, S.; Antony, J.; Ehrlich, S.; Krieg, H. A Consistent and Accurate Ab Initio Parametrization of Density Functional Dispersion Correction (DFT-D) for the 94 Elements H-Pu. J. Chem. Phys. 2010, 132 (15), 154104.

(34) Grimme, S.; Ehrlich, S.; Goerigk, L. Effect of the Damping Function in Dispersion Corrected Density Functional Theory. J. Comput. Chem. 2011, 32 (7), 1456-1465.

(35) Staroverov, V. N.; Scuseria, G. E.; Tao, J.; Perdew, J. P. Comparative Assessment of a New Nonempirical Density Functional: Molecules and Hydrogen-Bonded Complexes. J. Chem. Phys. 2003, 119 (23), 12129.

(36) Neese, F.; Wennmohs, F.; Hansen, A.; Becker, U. Efficient, Approximate and Parallel Hartree-Fock and Hybrid DFT Calculations. A "chain-of-Spheres" Algorithm for the Hartree-Fock Exchange. Chem. Phys. 2009, 356 (1-3), 98-109.

(37) Neese, F. The ORCA Program System. Wiley Interdiscip. Rev. Comput. Mol. Sci. 2012, 2 (1), 73-78.

(38) Cox, N.; Ames, W.; Epel, B.; Kulik, L. V.; Rapatskiy, L.; Neese, F.; Messinger, J.; 
Wieghardt, K.; Lubitz, W. Electronic Structure of a Weakly Antiferromagnetically Coupled Mn II Mn III Model Relevant to Manganese Proteins: A Combined EPR, ${ }^{55}$ Mn-ENDOR, and DFT Study. Inorg. Chem. 2011, 50 (17), 8238-8251.

(39) Pantazis, D. A.; Orio, M.; Petrenko, T.; Zanten, V.; Bill, E.; Lubitz, W.; Messinger, J.; Neese, F. A New Quantum Chemical Approach to the Magnetic Properties of Oligonuclear Transition-Metal Complexes: Application to a Model for the Tetranuclear Manganese Cluster of Photosystem II. Chem. - A Eur. J. 2009, 15 (20), 5108-5123.

(40) Sinnecker, S.; Neese, F.; Noodleman, L.; Lubitz, W. Calculating the Electron Paramagnetic Resonance Parameters of Exchange Coupled Transition Metal Complexes Using Broken Symmetry Density Functional Theory: Application to a Mn III /Mn IV Model Compound. J. Am. Chem. Soc. 2004, 126 (8), 2613-2622.

(41) Schinzel, S.; Kaupp, M. Validation of Broken-Symmetry Density Functional Methods for the Calculation of Electron Paramagnetic Resonance Parameters of Dinuclear Mixed-Valence Mn IV Mn III Complexes. Can. J. Chem. 2009, 87 (10), 1521-1539.

(42) Orio, M.; Pantazis, D. A.; Petrenko, T.; Neese, F. Magnetic and Spectroscopic Properties of Mixed Valence manganese(III,IV) Dimers: A Systematic Study Using Broken Symmetry Density Functional Theory. Inorg. Chem. 2009, 48 (15), 72517260 .

(43) Baffert, C.; Orio, M.; Pantazis, D. A.; Duboc, C.; Blackman, A. G.; Blondln, G.; Neese, F.; Deronzler, A.; Collomb, M. N. Trinuclear Terpyridine Frustrated Spin System with a $\mathrm{Mn}_{3}^{\mathrm{IV}}{ }_{3} \mathrm{O} 4$ Core: Synthesis, Physical Characterization, and Quantum Chemical Modeling of Its Magnetic Properties. Inorg. Chem. 2009, 48 (21), 1028110288 .

(44) Retegan, M.; Cox, N.; Lubitz, W.; Neese, F.; Pantazis, D. The First Tyrosyl Radical Intermediate Formed in the $\mathrm{S}_{2}-\mathrm{S}_{3}$ Transition of Photosystem II. Phys. Chem. Chem. Phys. 2014, 16 (24), 11901-11910.

(45) Styring, S.; Sjöholm, J.; Mamedov, F. Two Tyrosines That Changed the World: Interfacing the Oxidizing Power of Photochemistry to Water Splitting in Photosystem II. Biochim. Biophys. Acta - Bioenerg. 2012, 1817 (1), 76-87.

(46) Saito, K.; Shen, J.-R.; Ishida, T.; Ishikita, H. Short Hydrogen Bond between RedoxActive Tyrosine Yz and D1- His190 in the Photosystem II Crystal Structure. Biochemistry 2011, 50 (45), 9836-9844.

(47) Keough, J. M.; Jenson, D. L.; Zuniga, A. N.; Barry, B. A. Proton Coupled Electron Transfer and Redox-Active Tyrosine $\mathrm{Z}$ in the Photosynthetic Oxygen-Evolving Complex. J. Am. Chem. Soc. 2011, 133 (29), 11084-11087.

(48) Polander, B.; Barry, B. A. Calcium, Strontium, and Protein Dynamics during the S2 to S3 Transition in the Photosynthetic Oxygen-Evolving Cycle. J. Phys. Chem. Lett. 2013, 4 (19), 3356-3362.

(49) Saito, K.; Ishikita, H. Influence of the $\mathrm{Ca}(2+)$ Ion on the $\mathrm{Mn}_{4} \mathrm{Ca}$ Conformation and the H-Bond Network Arrangement in Photosystem II. Biochim. Biophys. Acta 2014, 
$1837(1), 159-166$.

(50) Polander, B.; Barry, B. A. Calcium and the Hydrogen-Bonded Water Network in the Photosynthetic Oxygen-Evolving Complex. J. Phys. Chem. Lett. 2013, 4 (5), 786791.

(51) Krewald, V.; Neese, F.; Pantazis, D. A. Redox Potential Tuning by Redox-Inactive Cations in Nature's Water Oxidizing Catalyst and Synthetic Analogues. Phys. Chem. Chem. Phys. 2016, 18 (16), 10739-10750.

(52) Kimura, Y.; Hasegawa, K.; Ono, T. Characteristic Changes of the $S_{2} / S_{1}$ Difference FTIR Spectrum Induced by $\mathrm{Ca}^{2+}$ Depletion and Metal Cation Substitution in the Photosynthetic Oxygen-Evolving Complex. Biochemistry 2002, 41 (18), 58445853.

(53) Rappaport, F.; Ishida, N.; Sugiura, M.; Boussac, A. Ca ${ }^{2+}$ Determines the Entropy Changes Associated with the Formation of Transition States during Water Oxidation by Photosystem II. Energy Environ. Sci. 2011, 4 (7), 2520-2524.

(54) Pitari, F.; Bovi, D.; Narzi, D.; Guidoni, L. Characterization of $\mathrm{Sr}^{2+}$ and $\mathrm{Cd}^{2+}$ Substituted Oxygen Evolving Complex of Photosystem II by QM/MM Calculations. Biochemistry 2015, 150908052718001.

(55) Nakamura, S.; Nagao, R.; Takahashi, R.; Noguchi, T. Fourier Transform Infrared Detection of a Polarizable Proton Trapped between Photooxidized Tyrosine $\mathrm{Y}_{\mathrm{Z}}$ and a Coupled Histidine in Photosystem II: Relevance to the Proton Transfer Mechanism of Water Oxidation. Biochemistry 2014, 53 (19), 3131-3144.

(56) O'Malley, P. J. Hybrid Density Functional Studies of the Oxidation of PhenolImidazole Hydrogen-Bonded Complexes: A Model for Tyrosine Oxidation in Oxygenic Photosynthesis. J. Am. Chem. Soc. 1998, 120 (45), 11732-11737.

(57) Engström, M.; Himo, F.; Gräslund, A.; Minaev, B.; Vahtras, O.; Agren, H. Hydrogen Bonding to Tyrosyl Radical Analyzed by Ab Initio G-Tensor Calculations. J. Phys. Chem. A 2000, 104 (21), 5149-5153.

(58) Engström, M.; Himo, F.; Ågren, H. Ab Initio G-Tensor Calculations of the Thioether Substituted Tyrosyl Radical in Galactose Oxidase. Chem Phys Lett 2000, $319(3-4), 191-196$.

(59) Matsuoka, H.; Shen, J.-R.; Kawamori, A.; Nishiyama, K.; Ohba, Y.; Yamauchi, S. Proton-Coupled Electron-Transfer Processes in Photosystem II Probed by Highly Resolved G -Anisotropy of Redox-Active Tyrosine YZ. J. Am. Chem. Soc. 2011, 133 (12), 4655-4660.

(60) Hart, R.; O'Malley, P. J. A Quantum Mechanics/molecular Mechanics Study of the Tyrosine Residue, Tyr $_{\mathrm{D}}$, of Photosystem II. Biochim. Biophys. Acta 2010, 1797 (2), 250-254.

(61) Saito, K.; Rutherford, A. W.; Ishikita, H. Mechanism of Tyrosine D Oxidation in Photosystem II. Proc. Natl. Acad. Sci. 2013, 110 (19), 7690-7695.

(62) Ioannidis, N.; Zahariou, G.; Petrouleas, V. The EPR Spectrum of Tyrosine Z and Its Decay Kinetics in $\mathrm{O}_{2}$ - Evolving Photosystem II Preparations. Biochemistry 2008, 47 
(24), 6292-6300.

(63) Fasanella, E. L.; Gordy, W. Electron Spin Resonance of an Irradiated Single Crystal of L-Tyrosine-Hcl. Proc. Natl. Acad. Sci. 1969, 62 (2), 299-304.

(64) Hoganson, C. W.; Tommos, C. The Function and Characteristics of Tyrosyl Radical Cofactors. Biochim. Biophys. Acta 2004, 1655 (1-3), 116-122.

(65) Mino, H.; Kawamori, A. EPR Studies of the Water Oxidizing Complex in the $\mathrm{S}_{1}$ and the Higher S States: The Manganese Cluster and Y(Z) Radical. Biochim. Biophys. Acta 2001, 1503 (1-2), 112-122.

(66) Hofbauer, W.; Zouni, A.; Bittl, R.; Kern, J.; Orth, P.; Lendzian, F.; Fromme, P.; Witt, H. T.; Lubitz, W. Photosystem II Single Crystals Studied by EPR Spectroscopy at 94 GHz: Proc. Natl. Acad. Sci. 2001, 98 (12), 6623-6628.

(67) Hogbom, M.; Galander, M.; Andersson, M.; Kolberg, M.; Hofbauer, W.; Lassmann, G.; Nordlund, P.; Lendzian, F. Displacement of the Tyrosyl Radical Cofactor in Ribonucleotide Reductase Obtained by Single-Crystal High-Field EPR and 1.4-A XRay Data. Proc. Natl. Acad. Sci. 2003, 100 (6), 3209-3214.

(68) Bleifuss, G.; Kolberg, M.; Pötsch, S.; Hofbauer, W.; Bittl, R.; Lubitz, W.; Gräslund, A.; Lassmann, G.; Lendzian, F. Tryptophan and Tyrosine Radicals in Ribonucleotide Reductase: A Comparative High-Field EPR Study at $94 \mathrm{GHz}$. Biochemistry 2001, 40 (50), 15362-15368.

(69) Benisvy, L.; Bittl, R.; Bothe, E.; Garner, C. D.; McMaster, J.; Ross, S.; Teutloff, C.; Neese, F. Phenoxyl Radicals Hydrogen-Bonded to Imidazolium: Analogues of Tyrosyl D. of Photosystem II: High-Field EPR and DFT Studies. Angew. Chemie Int. Ed. 2005, 44 (33), 5314-5317.

(70) Sinnecker, S.; Reijerse, E.; Neese, F.; Lubitz, W. Hydrogen Bond Geometries from Electron Paramagnetic Resonance and Electron-Nuclear Double Resonance Parameters: Density Functional Study of Quinone Radical Anion-Solvent Interactions. J. Am. Chem. Soc. 2004, 126 (10), 3280-3290.

(71) Sinnecker, S.; Flores, M.; Lubitz, W. Protein-cofactor Interactions in Bacterial Reaction Centers from Rhodobacter Sphaeroides R-26: Effect of Hydrogen Bonding on the Electronic and Geometric Structure of the Primary Quinone. A Density Functional Theory Study. Phys. Chem. Chem. Phys. 2006, 8 (48), 5659-5670.

(72) Nakazawa, S.; Ishii, A.; Minagawa, J.; Ono, T. Application of 2D-HYSCORE Spectroscopy to Tyrosine Radicals in Photosystem II for Evaluation of Spin Density Distributions. Chem. Phys. Lett. 2005, 405 (4-6), 318-322.

(73) Tommos, C.; Tang, X.-S.; Warncke, K.; Hoganson, C. W.; Styring, S.; McCracken, J.; Diner, B.; Babcock, G. T. Spin-Density Distribution, Conformation, and Hydrogen Bonding of the Redox-Active Tyrosine $\mathrm{Y}_{\mathrm{Z}}$ in Photosystem II from Multiple-Electron Magnetic-Resonance Spectroscopies: Implications for Photosynthetic Oxygen Evolution. J. Am. Chem. Soc. 1995, 117 (41), 10325-10335.

(74) O’Malley, P. J.; Ellson, D. ${ }^{1} \mathrm{H},{ }^{13} \mathrm{C}$ and ${ }^{17} \mathrm{O}$ Isotropic and Anisotropic Hyperfine Coupling Prediction for the Tyrosyl Radical Using Hybrid Density Functional 
Methods. Biochim. Biophys. Acta - Bioenerg. 1997, 1320 (1), 65-72.

(75) Rigby, S.; Nugent, J. H.; O’Malley, P. J. The Dark Stable Tyrosine Radical of Photosystem 2 Studied in Three Species Using ENDOR and EPR Spectroscopies. Biochemistry 1994, 1734-1742.

(76) Warncke, K.; McCracken, J.; Babcock, G. T. Structure of the YD Tyrosine Radical in Photosystem II as Revealed by ${ }^{2} \mathrm{H}$ Electron Spin Echo Envelope Modulation (ESEEM) Spectroscopic Analysis of Hydrogen Hyperfine Interactions. J. Am. Chem. Soc. 1994, 116 (16), 7332-7340.

(77) Debus, R. J.; Barry, B. A.; Sithole, I. Directed Mutagenesis Indicates That the Donor to P $680+$ in Photosystem II Is Tyrosine-161 of the D1 Polypeptide. Biochemistry 1988, 27 (26), 9071-9074.

(78) Rutherford, A. W.; Boussac, A.; Faller, P. The Stable Tyrosyl Radical in Photosystem II: Why D? Biochim. Biophys. Acta - Bioenerg. 2004, 1655 (1-3), 222-230.

(79) Pushkar, Y.; Yano, J.; Sauer, K.; Boussac, A.; Yachandra, V. K. Structural Changes in the $\mathrm{Mn}_{4} \mathrm{Ca}$ Cluster and the Mechanism of Photosynthetic Water Splitting. Proc. Natl. Acad. Sci. 2008, 105 (6), 1879-1884.

(80) Ugur, I.; Rutherford, A. W.; Kaila, V. R. I. Redox-Coupled Substrate Water Reorganization in the Active Site of Photosystem II - The Role of Calcium in Substrate Water Delivery. Biochim. Biophys. Acta - Bioenerg. 2016, 1857 (6), 740748.

(81) Haumann, M.; Müller, C.; Liebisch, P.; Iuzzolino, L.; Dittmer, J.; Grabolle, M.; Neisius, T.; Meyer-Klaucke, W.; Dau, H. Structural and Oxidation State Changes of the Photosystem II Manganese Complex in Four Transitions of the Water Oxidation Cycle $\left(S_{0}->S_{1}, S_{1}->S_{2}, S_{2}->S_{3}\right.$, and $\left.S_{3,4}->S_{0}\right)$ Characterized by X-Ray Absorption Spectroscopy at $20 \mathrm{~K}$ and Room Temperature. Biochemistry 2005, 44 (6), 1894-1908.

(82) Glöckner, C.; Kern, J.; Broser, M.; Zouni, A.; Yachandra, V. K.; Yano, J. Structural Changes of the Oxygen-Evolving Complex in Photosystem II during the Catalytic Cycle. J. Biol. Chem. 2013, 288 (31), 22607-22620.

(83) Bencini, A.; Gatteschi, D. Electron Paramagnetic Resonance of Exchange Coupled Systems; Springer Berlin Heidelberg: Berlin, Heidelberg, 1990.

(84) Krewald, V.; Neese, F.; Pantazis, D. A. On the Magnetic and Spectroscopic Properties of High-Valent $\mathrm{Mn}_{3} \mathrm{CaO}_{4}$ Cubanes as Structural Units of Natural and Arti Fi Cial Water- Oxidizing Catalysts. J. Am. Chem. Soc. 2013, 135 (15), 5726-5739.

(85) Kanady, J. S.; Tsui, E. Y.; Day, M. W.; Agapie, T. A Synthetic Model of the Mn3Ca Subsite of the Oxygen-Evolving Complex in Photosystem II. Science (80-. ). 2011, 333 (6043), 733-736.

(86) Tsui, E. Y.; Kanady, J. S.; Agapie, T. Synthetic Cluster Models of Biological and Heterogeneous Manganese Catalysts for $\mathrm{O}_{2}$ Evolution. Inorg. Chem. 2013, 52 (24), 13833-13848. 
(87) Shoji, M.; Isobe, H.; Shen, J.-R.; Yamaguchi, K. Geometric and Electronic Structures of the Synthetic $\mathrm{Mn}_{4} \mathrm{CaO}_{4}$ Model Compound Mimicking the Photosynthetic Oxygen-Evolving Complex. Phys. Chem. Chem. Phys. 2016, 18, 11330-11340.

(88) Mukhopadhyay, S.; Mandal, S. K.; Bhaduri, S.; Armstrong, W. H. Manganese Clusters with Relevance to Photosystem II. Chem. Rev. 2004, 104 (9), 3981-4026.

(89) Krewald, V.; Retegan, M.; Cox, N.; Messinger, J.; Lubitz, W.; DeBeer, S.; Neese, F.; Pantazis, D. A. Metal Oxidation States in Biological Water Splitting. Chem. Sci. 2015, 6 (3), 1676-1695.

(90) Sanakis, Y.; Sarrou, J.; Zahariou, G.; Petrouleas, V. Q-Band Electron Paramagnetic Resonance Studies of the $\mathrm{S}_{3}$ State of the OEC of Photosystem II. In Photosynthesis. Energy from the Sun: 14th International Congress on Photosynthesis; Allen, J.F. Gantt , E. Golbeck, J.H. Osmond, B., Ed.; Springer, 2008; pp 479-482.

(91) Boussac, A.; Sugiura, M.; Rutherford, A. W.; Dorlet, P. Complete EPR Spectrum of the S3-State of the Oxygen-Evolving Photosystem II. J. Am. Chem. Soc. 2009, 131 (14), 5050-5051.

(92) Renger, G. Mechanism of Light Induced Water Splitting in Photosystem II of Oxygen Evolving Photosynthetic Organisms. Biochim. Biophys. Acta - Bioenerg. 2012, 1817 (8), 1164-1176.

(93) Isobe, H.; Shoji, M.; Shen, J.-R.; Yamaguchi, K. Chemical Equilibrium Models for the $\mathrm{S}_{3}$ State of the Oxygen-Evolving Complex of Photosystem II. Inorg. Chem. 2016, 55 (2), 502-511.

(94) Nilsson, H.; Rappaport, F.; Boussac, A.; Messinger, J. Substrate-Water Exchange in Photosystem II Is Arrested before Dioxygen Formation. Nat. Commun. 2014, 5, 1-7. 
TOC Graphic
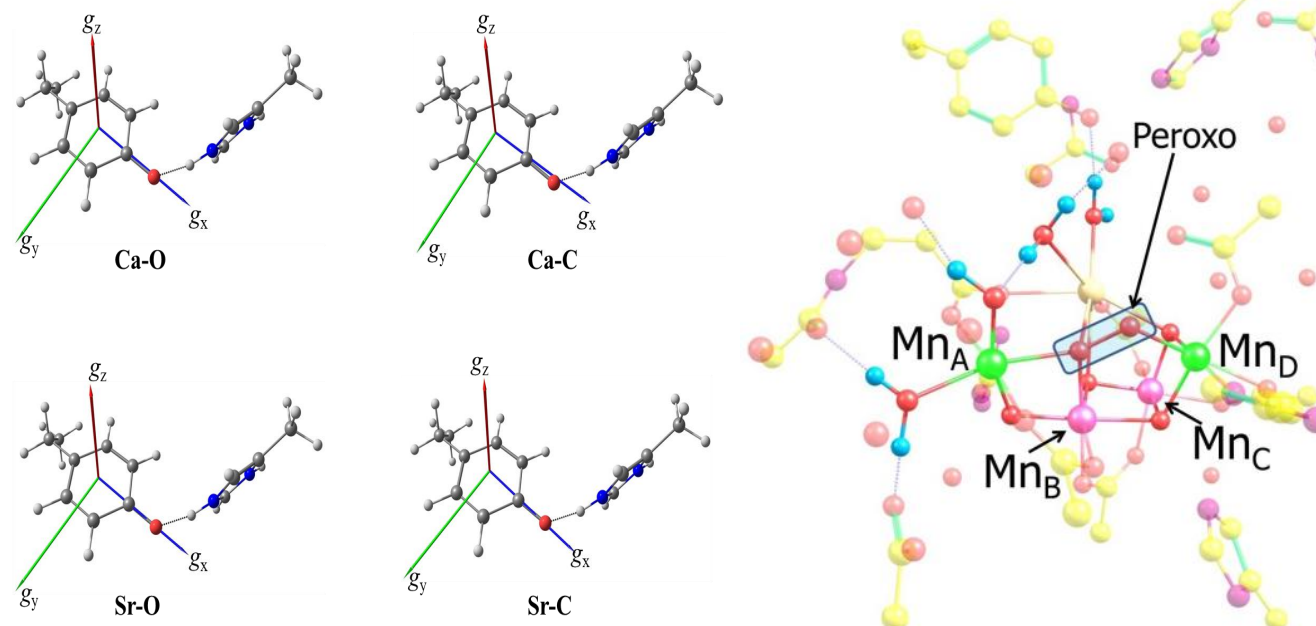